NBER WORKING PAPER SERIES

\title{
HOW ELASTIC ARE PREFERENCES FOR REDISTRIBUTION? EVIDENCE FROM RANDOMIZED SURVEY EXPERIMENTS
}

\author{
Ilyana Kuziemko \\ Michael I. Norton \\ Emmanuel Saez \\ Stefanie Stantcheva \\ Working Paper 18865 \\ http://www.nber.org/papers/w18865 \\ NATIONAL BUREAU OF ECONOMIC RESEARCH \\ 1050 Massachusetts Avenue \\ Cambridge, MA 02138 \\ March 2013
}

We thank co-editor Marianne Bertrand, Raj Chetty, Amy Finkelstein, Ray Fisman, Lawrence Katz, Wojciech Kopczuk, James Poterba, Andrea Prat, Jonah Rockoff, four anonymous referees, and numerous seminar and conference participants for helpful comments and discussions. Pauline Leung provided outstanding research assistance. Financial support from the Center for Equitable Growth at UC Berkeley, the MacArthur Foundation, and NSF Grant SES-1156240 is gratefully acknowledged. The views expressed herein are those of the authors and do not necessarily reflect the views of the National Bureau of Economic Research.

NBER working papers are circulated for discussion and comment purposes. They have not been peerreviewed or been subject to the review by the NBER Board of Directors that accompanies official NBER publications.

(C) 2013 by Ilyana Kuziemko, Michael I. Norton, Emmanuel Saez, and Stefanie Stantcheva. All rights reserved. Short sections of text, not to exceed two paragraphs, may be quoted without explicit permission provided that full credit, including (C) notice, is given to the source. 
How Elastic Are Preferences for Redistribution? Evidence from Randomized Survey Experiments Ilyana Kuziemko, Michael I. Norton, Emmanuel Saez, and Stefanie Stantcheva

NBER Working Paper No. 18865

March 2013, Revised December 2014

JEL No. D63,D72,H2,I3

\begin{abstract}
$\underline{\text { ABSTRACT }}$
We develop online survey experiments to analyze how information about inequality and taxes affects preferences for redistribution. Approximately 4,000 respondents were randomized into treatments providing interactive, customized information on U.S. income inequality, the link between top income tax rates and economic growth, and the estate tax. An additional 6,000 respondents were randomized into follow-up treatments to explore mechanisms underlying the initial results. The treatment has very large effects on whether respondents view inequality as a problem. By contrast, it only slightly moves policy preferences (e.g., top income tax rates and transfer programs). An exception is the estate taxinforming respondents of the small share of decedents who pay it more than doubles support for it and this effect persists in a one-month follow-up. We explore several explanations for our results. Extreme ex-ante misinformation appears to drive the large estate tax results. The small effects for all other policies can be at least partially explained by respondents' low trust in government-indeed, we show that priming people to think negatively about the government substantially reduces support for transfer programs - as well as a disconnect between concerns about social issues and the public policies that aim to address them.
\end{abstract}

Ilyana Kuziemko

Department of Economics

Princeton University

Wallace Hall

Princeton, NJ 08544

and NBER

kuziemko@princeton.edu

Michael I. Norton

Marketing Unit

Harvard Business School

Boston, MA 02163

mnorton@hbs.edu
Emmanuel Saez

Department of Economics

University of California, Berkeley

530 Evans Hall \#3880

Berkeley, CA 94720

and NBER

saez@econ.berkeley.edu

Stefanie Stantcheva

Department of Economics

Littauer Center 232

Harvard University

Cambridge, MA 02138

and NBER

sstantcheva@fas.harvard.edu 
The past several decades have seen a large increase in income concentration in the United States. While the top one percent of families captured 9.0 percent of total pre-tax income in 1970, that share rose to 22.4 percent by $2012 .{ }^{1}$ More recent work has documented a corresponding trend for wealth concentration: the top 0.1 percent share of wealth has grown from 8 percent in the mid-1970s to 22 percent in 2012 (Saez and Zucman, 2014). These trends have not gone unnoticed, at least by some. The Occupy Wall Street movement popularized the term "the one percent." Recently, President Obama has called "a dangerous and growing inequality" the "defining challenge of our time," a sentiment echoed by the CEO of Goldman Sachs, who told an interviewer that "too much of the GDP of the country has gone to too few of the people." 2

There is a large theoretical literature on the link between inequality and redistribution. The most widely used median-voter model predicts that a widening gap between the average and the median income should lead to an increase in redistribution, as politicians respond to the median voter's preferences (Meltzer and Richard, 1981). By contrast, top income tax rates as well as inheritance tax rates have fallen in the United States during this period. ${ }^{3}$ While for institutional reasons the policy views of the majority might be ignored by policy-makers (Bartels, 2009), even more challenging to the model's predictions is that survey respondents themselves show no increased demand for redistribution since the $1970 \mathrm{~s} .{ }^{4}$ If anything, the General Social Survey shows that there has been a slight decrease in stated support for redistribution in the United States since the 1970s, even among those who self-identify as having below-average income (see Figure 1). These trends have led commentators to suggest that Americans simply do not care about rising inequality. ${ }^{5}$

There are alternative explanations: Americans may be unaware of the extent or growth of inequality (see Kluegel and Smith, 1986 and Norton and Ariely, 2011), this information may not be sufficiently salient, or they are skeptical about the government's ability to redistribute

\footnotetext{
${ }^{1}$ See the online updates to Piketty and Saez (2003), Table A3 at http://elsa.berkeley.edu/ saez/TabFig2012prel.xls

${ }^{2}$ See http://www. whitehouse.gov/the-press-office/2013/12/04/remarks-presidenteconomic-mobility and http://thinkprogress.org/economy/2014/06/13/3448679/goldmansachs-income-inequality/, respectively.

${ }^{3}$ For top income tax rates, see Piketty, Saez, and Stantcheva (2014) and for estate taxes see IRS calculations at http://www.irs.gov/pub/irs-soi/ninetyestate.pdf.

${ }^{4}$ See, e.g., Kenworthy and McCall (2008), for evidence from a variety of OECD countries that saw increases in inequality but no corresponding increase in redistributive demand.

${ }^{5}$ As Newsweek put it in 2001: "If Americans couldn't abide rising inequality, we'd now be demonstrating in the streets."
} 
effectively. ${ }^{6}$ In this paper, we extensively examine these explanations. We conduct a series of randomized survey experiments using Amazon's Mechanical Turk (mTurk). mTurk is a rapidly growing online platform that can be used to carry out social and survey experiments (see Horton, Rand, and Zeckhauser, 2011 and Paolacci, Chandler, and Ipeirotis, 2010). In our initial set of experiments, comprising just over 4,000 respondents, half of respondents were randomized into an "omnibus" treatment providing interactive, personalized information on U.S. income inequality, the historical correlation between top income tax rates and economic growth, and the incidence of the estate tax. Both control and treatment groups then reported their views on inequality, redistributive policies, and government more generally. We then conducted follow-up experiments with about 6,000 new respondents to analyze potential mechanisms behind the initial results, for a total of approximately 10,000 respondents. ${ }^{7}$

Our treatments exploit the flexibility of the mTurk platform to include several features that heighten the salience of the information we present. First, some of the information we present is customized. For example, we ask individuals their household income, allowing us to show them their place in the income distribution, as well as their counterfactual income level had aggregate income growth since 1980 been distributed more equally (so as to leave inequality unchanged). In other parts of the survey, we customize information based on respondents' own household composition. ${ }^{8}$ Second, some of the information is interactivefor example, our survey allows respondents to enter different household income levels and the software survey application provides the corresponding percentile, so that the income distribution can be transparently explored.

The initial survey experiment provides several findings we believe to be novel relative to existing literature; the first part of the paper provides a descriptive analysis of these results. First, we find that respondents' concern about inequality is very elastic to information-

${ }^{6} \mathrm{~A}$ number of alternative theoretical models make different predictions than the median voter model. Corneo and Gruner (2000) propose a model with status effects where the middle class opposes redistribution when this leads to more social competition with bottom income earners. Alesina and Angeletos (2005); Piketty (1995) show that different beliefs on the role of effort vs. luck in success can lead to multiple redistributive equilibria. Benabou and Ok (2001) show that the prospect for upward mobility can limit the desire for redistribution. There is also a wide empirical literature on the determinants of preferences for redistribution (see e.g., Corneo and Gruner (2002), Guillaud (2013), and Senik (2009) for evidence from cross-country survey data).

${ }^{7}$ Survey questions and treatments are all available online at https: //hbs . qualtrics . com/SE/?SID=SV_77fSvTy12ZSBihn.

${ }^{8}$ Recent work has highlighted the potential power of customizing information in interventions. For example, Hoxby and Turner (2013) credit the customized nature of the information they present to students for the large effects their intervention had on college application decisions. 
for example, the treatment increases the share agreeing that inequality is a "very serious problem" by over 35 percent. Put differently, the treatment effect is equal to roughly 36 percent of the gap between self-identified liberals and self-identified conservatives on this question. By contrast, while there are some effects on policy preferences such as top income tax rates, the minimum wage and food stamps (always in the "expected" direction), they are small and often insignificant despite the large sample size.

The only exception is the estate tax - we find that providing information on the (small) share of estates subject to the tax more than doubles respondents' support for increasing it. Focusing on the estate tax result, we attempt to make progress on two long-standing critiques about survey analysis: that the effects are ephemeral and unrelated to actual behavior. We benefit from the mTurk technology and re-survey respondents one month later: the estate tax effect is virtually unchanged. We also find that the treatment significantly increases the share of respondents who say they would send a petition to one of the U.S. Senators from their state to raise the estate tax.

The second half of the paper explores the mechanisms behind the large estate-tax effects and the muted response for any other policy outcome. Of course, other explanations may exist and as such we do not view our attempts to tease out the mechanisms behind the main results as definitive. Consistent with past work, we find that respondents are wildly misinformed about the share of decedents subject to the estate tax, which appears to account for the large effects. We further show that the estate tax effect remains strong even when we take steps to decrease the salience and emotional content of the information provided, further proof that more information on this issue has large effects.

We test three potential explanations for the small effects for other policies: limited trust in government; an overly "clinical" presentation of information; and respondents' inability to connect their concerns on a given issue with the public policies meant to address it.

The first potential explanation is that distrust in government inhibits respondents from translating concern for inequality into support for redistribution by the government. Several results from the original survey experiment point in this direction. First, our initial treatment significantly decreases trust in government. When reminded of the extent of inequality (which even control group respondents view as a problem), those in the treatment group appear to at least partially blame the government, perhaps thinking that if politicians "let things get this bad" they cannot be trusted to fix it. Second, beyond any treatment effect, the level of government trust among our sample of mTurk respondents is very low: over 89 
percent agree that "Politicians in Washington work to enrich themselves and their largest campaign contributors, instead of working for the benefit of the majority of citizens," with 47 percent "strongly" agreeing. It is thus perhaps not surprising that even when the treatment increases respondents' concern with inequality, they remain reluctant to increase support for government redistributive policies.

In a follow-up survey experiment, we provide direct evidence for the effect of trust in government on respondents' policy preferences. We first asked a small pilot group to answer open-ended questions on their views of government - the main theme that emerges is that politicians are believed to work to enrich themselves and their wealthiest campaign donors. We then used these answers to develop "primes" (e.g., asking respondents' opinions about lobbyists or the Wall Street bailout) that significantly lowered trust in government without significantly changing views about the extent of inequality or poverty. Therefore, the treatment isolates the causal effect of decreasing trust in government. We find that the treatment significantly lowers support for all poverty-alleviation policies, with the exception, interestingly, of the minimum wage - a program that does not involve direct transfers from the government. Support for top tax rates generally falls as well (though only some of these effects are significant) and respondents elevate "private charity" over government policies in a list of the best ways to combat inequality. This analysis provides, to our knowledge, the first direct evidence on the causal effects of trust in government on policy preferences, and is particularly relevant given the historically low regard with which Americans currently view their government. ${ }^{9}$

Besides distrust muting the policy effects of our treatment, we explore two other potential explanations for the small results in the original survey experiment. As Brader (2005) and others argue, policy preferences might respond more to emotional than factual appeals. We thus develop a treatment - again, interactive and customized - designed to evoke empathy for households at the poverty line. Just as in the initial survey experiment, the treatment significantly increases respondents' tendency to view inequality and poverty as "serious problems" but has almost no effect on policy preferences.

We find more support for a third explanation, the idea in Bartels (2005) that the public

\footnotetext{
${ }^{9}$ See analysis from Gallup: http://www.gallup.com/poll/164663/americans-trustgovernment-generally-down-year.aspx. The General Social Survey also shows a strongly negative trend. Related to our finding, Yamamura (2014) finds that above average income respondents in Japan are more likely to support redistribution when trust in government in their residential area is high.
} 
fails to connect concern for inequality with actual public policy measures. To test this idea, we repeat much of the information in the "emotional appeal" treatment, but then show respondents concretely the resources provided to such families through government programs including the minimum wage and food stamps. Therefore, the treatment directly connects poverty and inequality with policies meant to address them. Emphasizing this connection appears important: treatment respondents significantly increase their support for the minimum wage as well as most of the poverty-alleviation programs that we survey. We view this result as potentially complementary to the trust results: given the low baseline levels of trust, it appears to be the case that policy preferences can only be moved if respondents are explicitly reminded of efficacious examples of government intervention.

We believe our findings make several contributions to the understanding of how individuals form - and change - their redistributive preferences. Compared to most informational interventions that merely provide a fixed set of facts to respondents, our informational treatments were interactive and customized - while perhaps not providing a strict upper bound on the effects of information on preferences, our results do suggest that most policy preferences are hard to move. This finding echoes Luttmer and Singhal (2011) that redistributive preferences may have "cultural" determinants that are very stable over time.

Our results also highlight the potential role of mistrust of government in limiting the public's enthusiasm for policies they would otherwise appear to support, a subject that has garnered limited attention in the economics literature. An exception is Sapienza and Zingales (2013), who find that a major reason respondents support auto fuel standards over a gasolinetax-and-rebate scheme is not because they misunderstand the incidence of fuel standards but because they simply do not trust the government to actually rebate them their money.

More generally, our paper relates to the literature on the determinants of redistributive preferences, to which political scientists, sociologists, psychologists and public economists have all contributed. Many papers in this literature use survey data to relate individual traits to redistributive preferences and do not, as we do, take an experimental approach. Alesina and Ferrara (2005), Alesina and Giuliano (2011), and Fong (2001) show that, respectively, prospects for future income mobility, past experience of misfortune, and beliefs about equality of opportunity predict redistributive preferences. Other papers have examined how situational factors (employment status, neighborhood characteristics) predict preferences (see, e.g., Margalit 2013, Luttmer 2001). Singhal (2008) uses OECD survey data to show that people do not necessarily favor low tax rates at income levels close to theirs, 
suggesting that redistributive preferences are not completely determined by self-interest.

As in our paper, some researchers have estimated the effects of randomized informational treatments on policy preferences. ${ }^{10}$ The evidence from these efforts is mixed. Sides (2011) finds that providing information on the very small number of individuals affected by the estate tax drastically decreases support for its repeal, results that we replicate with our data. Cruces, Perez-Truglia, and Tetaz (2013) find that showing poor individuals their actual place in the income distribution increases their support for policies that target poverty, as most overestimate their income. On the other hand, Kuklinski et al. (2003) find that providing (accurate) information on the demographic composition of welfare recipients and the share of the federal budget dedicated to welfare payments has no effect on respondents' preferences, despite the fact that their initial beliefs are wildly incorrect. ${ }^{11}$ We examine a wide variety of redistributive policy outcomes; indeed, we find that the responsiveness of views on the estate tax appears to be an outlier and other outcomes suggest a far more modest effect of information on redistributive preferences.

As noted, our research is part of a small but growing set of papers using online platforms. Researchers have used these platforms - most often, mTurk - to have respondents play public goods games (e.g., Rand and Nowak, 2011, Suri and Watts, 2010), interact in online labor markets (Amir, Rand, and Gal 2012; Horton, Rand, and Zeckhauser 2011), or simply answer non-experimental survey questions on views about policy and social preferences (Weinzierl 2012; Saez and Stantcheva 2013). We summarize our experience conducting survey experiments on mTurk in the online Methodological Appendix, which we hope can be of use to future researchers utilizing this platform.

The paper proceeds as follows. Section 1 introduces the initial survey instrument and data collection procedures. Section 2 describes the data. Section 3 presents the main results of the survey experiment. In Section 4, we explore mechanisms behind the large effects of information on views about the estate tax and why most other effects were so limited, reporting methods and results from four follow-up survey experiments. Finally, in Section 5, we suggest directions for future work and offer concluding thoughts. All our online surveys, data, and programs are available in the online appendix.

\footnotetext{
${ }^{10}$ While not related to policy preferences, there is a small literature on how information treatments affect individuals' ability to better navigate policies such as Social Security (Liebman and Luttmer, 2011).

${ }^{11}$ Related but distinct from informational treatments are priming and presentational treatments (see, e.g., Savani and Rattan 2012 on the effect of priming free will and McCaffery and Baron 2006 on the effects of presenting taxes in absolute or percentage terms).
} 


\section{The Main Survey Experiment}

The main experiment was implemented in four separate rounds from January 2011 to August 2012. For expositional clarity, to distinguish this initial experiment from the follow-up work we describe in Section 4, we refer to these four initial rounds of surveys as the "omnibus" treatment surveys. The omnibus treatment surveys had the following structure: (1) background socio-economic questions including typical demographic questions as well as political leanings; (2) randomized treatment providing information on inequality and tax policy (shown solely to the treatment group); (3) questions on views on inequality, tax and transfer policies, and government more generally. ${ }^{12}$

\subsection{Data collection}

Surveys were openly posted on mTurk with a description stating that the survey paid $\$ 1.50$ for approximately 15 minutes, i.e., a $\$ 6$ hourly wage. Respondents were free to drop out any time or take up to one hour to answer all questions. As a comparison, the average effective wage on mTurk according to Amazon is around $\$ 4.80$ per hour and most tasks on mTurk are short (less than one hour). ${ }^{13}$

Several steps were taken to ensure the validity of the results. First, there are many foreign workers on mTurk, especially from Asia. In addition to requiring respondents to confirm their U.S. residency on the consent form, we also had Amazon show the survey only to workers who had U.S. addresses. Second, to further discourage foreign workers, we tried to launch our surveys during East Coast daylight hours (and, to reduce heterogeneity, only on workdays). Third, to exclude robots, only workers with a past completion rate of at least ninety percent were allowed to take the survey. Fourth, as our survey comprises many rounds, we screen out workers who had participated in a previous round of the survey. Fifth, respondents were told that payment would be contingent on completing the survey and providing a password visible only at completion. Finally, to discourage respondents from skipping mindlessly through the pages, pop-up windows with an encouragement to answer all questions appeared as prompts whenever a question was left blank.

\footnotetext{
${ }^{12}$ The Appendix provides a complete description of the experiment with the questions for each round of the main experiments, and the follow-up experimental rounds discussed later in the paper.

${ }^{13}$ To gauge the external validity of the mTurk results, we gathered data for round 3 using C\&T Marketing (http://www.ctmarketinggroup.com/). As noted in Section 3, effects are stable across rounds, suggesting that respondents from the two platforms respond similarly to the treatment. Per-participant costs for C\&T are roughly five times higher than for mTurk.
} 


\subsection{The omnibus information treatment}

In general, the goal of the information treatments was to provide a large "shock" to individuals' knowledge about inequality and redistributive policies, rather than to provide a Ph.D-level, nuanced discussion about, say, the underlying causes of inequality or the trade-off between equality and efficiency. Hence, some of the treatments we display will seem overly simplified to an economics audience, but it should be kept in mind that our goal in the initial experiment is to test whether any treatment can move redistributive preferences; thus we erred on the side of presenting information we thought would indeed move those preferences. As noted in the introduction, we took steps to make the information both interactive and customized to each respondent.

The treatment had three basic parts. First, treatment respondents saw interactive information on the current income distribution - they were asked to input their household income and were then told what share of households made more or less than their household. We also asked them to find particular points in the distribution - they were asked to find the median and the $90^{\text {th }}$ and $99^{\text {th }}$ percentiles and were encouraged to "play around" with the application. Appendix Figure 1 presents a screen shot. ${ }^{14}$

The second part focused not on the current distribution but a counterfactual: respondents entered their current income and were then shown what they "would have made" had economic growth since 1980 been evenly shared across the income distribution (i.e., had the level of inequality stayed the same as in 1980). Of course, this exercise abstracts away from the trade-off between efficiency (economic growth) and equality that would certainly exist at very high levels of taxation. The interactive application allowed them to find this counterfactual value for any point of the current income distribution. Appendix Figure 2 presents a screen shot.

The third part of the treatment focused on redistributive policies. To emphasize that higher income taxes on the well-off need not always lead to slower economic growth, we presented respondents a figure showing that, at least as a raw correlation, economic growth, measured by average real pre-tax income per family from tax return data, has been slower

\footnotetext{
${ }^{14}$ As detailed in Appendix Table 1 we also ask treatment respondents six "basic comprehension" questions to determine if the information was confusing. With one exception, each question exhibits at least eighty percent comprehension. Moreover, more than 74 percent of respondents answer at least five of the six questions correctly. There are no differential treatment effects by comprehension level (results available upon request), not surprising given that comprehension is at a fairly high (and uniform) level.
} 
during periods with low top tax rates (1913 to 1933 and 1980 to 2010) than with high top tax rates (1933 to 1980). Appendix Figure 3 presents a screen shot. Similarly, we also presented a slide on the estate tax, emphasizing that it currently only affects the largest 0.1 percent of estates and that it favors intergenerational mobility. Appendix Figure 4 shows a screen shot.

Readers can directly experience these informational treatments online at the link below. ${ }^{15}$ We describe the additional treatments in the follow-up surveys in Section 4.

\section{Data}

\subsection{Summary statistics}

Table 1 shows characteristics of the sample who completed the omnibus treatment survey rounds (we discuss attrition below). We compare these summary statistics to a nationally representative sample of U.S. adults contacted by a CBS poll in 2011, which we choose both because it was conducted around the same time as our surveys and asks very similar questions. ${ }^{16}$ We also compare it to a more representative (though far more expensive) online panel survey gathered by RAND, the American Life Panel (ALP). ${ }^{17}$

Our sample is younger, more educated and has fewer minorities. It is more liberal, with a higher fraction reporting having supported President Obama in the 2008 election. ${ }^{18}$

Table 2 shows summary statistics on demographic and policy views for self-reported liberals (col. 1) and conservatives (col. 2) from our control group (so that responses are not contaminated by the information treatment), as well as the entire control group (col. 3). As expected, conservatives are older, more white, and more likely to be married. They prefer lower taxes on the rich and a less generous safety net. Such contrasts are useful to scale

\footnotetext{
${ }^{15}$ See https://hbs.qualtrics.com/SE/?SID=SV_77fSvTy12ZSBihn. Note that the control group went straight from the background questions to the outcomes measures (starting with the preferred tax rates sliders).

${ }^{16}$ Note that the CBS sample is not as representative as the traditional surveys used by economists such as the Current Population Survey or the American Community Survey. However, these two surveys do not have questions on past voting behavior or political preferences, so we rely on the admittedly less representative CBS survey.

${ }^{17}$ The ALP currently costs researchers $\$ 3$ per subject per minute, compared to roughly $\$ .10$ per subject per minute for our mTurk surveys. The ALP survey is also limited in sample size.

${ }^{18}$ As a robustness check, we created weights to match our mTurk sample in col. (1) to the CBS poll in col. (2) with respect to the 32 cells based on: gender $(2) \times$ age brackets $(2) \times$ white versus non-white $(2) \times$ college degree indicator $(2) \times$ Supported Obama in $2008(2)$. Reweighting has no appreciable effects on the results in Tables 4 and 5 (results available upon request) and thus we focus on the unweighted results in the paper.
} 
the magnitude of our effects. We will often discuss treatment effects both in absolute terms and as a percentage of the liberal-versus-conservative differences reported in Table 2. For convenience, we refer to this difference as the "political gap" for a given outcome variable.

\section{$2.2 \quad$ Survey attrition}

The omnibus survey experiment had an overall attrition rate of 22 percent, which includes those who attritted as early as the consent page. For those who remained online long enough to be assigned a treatment status, attrition was 15 percent.

As Appendix Table 2 shows, attrition is not random, though it is unrelated to 2008 voting preferences and liberal versus conservative policy views (the variables most highly correlated with our outcome variables). The online survey for the treatment group was, by necessity, different from the online survey for control group. Therefore, a key concern is differential attrition between those assigned to the treatment versus control arms. As the final row of Table 2 shows, attrition is higher among the treatment group (twenty percent, versus nine percent for the control group). ${ }^{19}$

Importantly, however, conditional on finishing the survey, assignment to treatment appears randomly assigned. That is, while the treatment induces attrition overall, it does not induce certain groups to differentially quit the survey more than others. Table 3 shows the results from estimating (using the sample who complete the survey) 14 separate regressions of the form: Treatment $_{i r}=\beta$ Covariate $_{i r}+\delta_{r}+\epsilon_{i r}$, where $i$ indexes the individual, $r$ the survey rounds, and $\delta_{r}$ are survey-round fixed effects. ${ }^{20}$ For each regression, one of the control variables in Table 2 serves as Covariate. Of the 14 regressions, only two (for the black and Hispanic indicators) yield significant coefficients on the Covariate variable. However, given that their point-estimates have opposite signs, it does not seem that, say, minorities systematically attrit from the sample if they are assigned to the treatment.

While we will control for these covariates as well as perform additional checks of attrition in the analysis that follows, it is reassuring to see that, conditional on finishing the survey, there does not appear to be a discernible pattern in the types of respondents assigned to

\footnotetext{
${ }^{19}$ For this comparison, we can obviously only include individuals who remained in the survey long enough to have been assigned a treatment status. The other comparisons in this table include all those who remained long enough to answer the given covariate question.

${ }^{20} \mathrm{We}$ include round fixed effects $\delta_{r}$ because in one round we assigned more than half the respondents to the treatment. As such, without round fixed effects, Treatment becomes mechanically correlated to the characteristics of respondents in this round.
} 
treatment. We are quite fortunate in this regard, as one might have expected that groups pre-disposed against reading about inequality - perhaps conservatives or wealthier peoplewould have been "turned off" by the treatment and differentially attritted. The follow-up surveys discussed in Sections 4 have essentially zero differential attrition by treatment status (see Appendix Table 3), most likely because the treatments in the follow-up surveys are much shorter (making the treatment and control arms of the survey much closer in length).

\section{Results from the omnibus treatment}

We present three sets of results. First, we analyze how the treatment affects respondents' answers to questions related to inequality per se, not policies that might affect it. Second, we analyze specific policies - e.g., raising taxes or increasing the minimum wage. Third, we analyze respondents' views about government as well as their political engagement.

\subsection{Views on inequality}

Table 4 presents the effect of the omnibus treatment on questions related to inequality. Odd-numbered columns do not include any controls outside of round fixed effects, while even-numbered columns include standard controls (essentially, those listed in Table 3). ${ }^{21}$

Col. (1) shows that the treatment is associated with a ten-percentage-point (or 36 percent) increase in the share agreeing that inequality is a "very serious" problem. Similarly, dividing the point-estimate by the 'political gap' (i.e., the liberal-conservative control group difference for the outcome variable) suggests that the treatment effect is equal to 36 percent of the political gap on this question (equal to 38 points in Table 2). While a convenient scaling, dividing by the political gap is hardly a perfect metric - while political views are highly predictive of many of our outcomes, this tendency varies and therefore some questions have larger political gaps than others. We thus report both the absolute and scaled effects for all regressions. Adding covariates in col. (2) has no effect on the estimated treatment effect.

The effects on the outcome "did inequality increase since 1980?" are presented in columns (3) and (4) and are even larger both in absolute percentage points and when scaled by the political gap (54 percent of the conservative-liberal difference), likely because the informational

\footnotetext{
${ }^{21}$ Specifically, we include fixed effects for racial/ethnic categories, employment status, and state of residence; indicator variables for voting for Barack Obama in 2008, being married, gender, and native-born status; continuous controls for age; and categorical variables for the liberal-toconservative self-rating, household income, and education.
} 
treatment presented information directly related to the question.

The effects on respondents' opinion of whether the rich are deserving of their income are presented in columns (5) and (6). They are statistically significant, but markedly smaller in magnitude - equal to about five percentage points, or one-sixth the political gap. Therefore, it does not seem that treatment respondents' concern about inequality is being driven primarily by a vilification of the rich.

In no case does the choice to exclude or include controls change the results (consistent with the results from Table 3 that conditional on finishing the survey, there was little correlation between treatment status and standard covariates). Therefore, to conserve space and reduce noise, we show all results with covariates in the rest of the analysis.

Overall, our omnibus treatment generated a very strong "first stage," significantly shifting views about inequality and its increase in recent decades.

\subsection{Views on public policy}

Table 5 presents results for questions related to income and estate taxation. The first two columns report results from the two questions on income taxation - a continuous variable asking respondents to choose an ideal average tax rate for the richest one percent and a categorical variable asking them whether taxes on millionaires should be raised - show statistically significant effects of the treatment, in the "expected" direction. ${ }^{22}$ However, these magnitudes are small, equal to about ten percent of the liberal-conservative gap in both cases. For example, the treatment increases the preferred top 1 percent average tax rate by 0.93 percentage points, whereas the gap between liberals and conservatives on this question is slightly over ten percentage points (see Table 2). Hence, we can rule out an effect on the tax rate for the top 1 percent larger than 20 percent of the liberal conservative gap.

The omnibus treatment was hardly subtle in its discussion of income taxes, focusing on how income growth might be shared more equitably through higher taxation and illustrating the temporal correlation between periods of high top tax rate and strong economic growth. We also asked the income tax question in two different ways, so the small magnitude of the results is unlikely to be an artifact of framing.

By contrast, there are very large effects for the estate tax (col. 3), consistent with Sides (2011). The treatment triples the share of respondents supporting an increase in the estate tax, and the effect size is more than double the liberal-conservative gap on this question. We

\footnotetext{
${ }^{22}$ See Appendix Figure 5 for the screen respondents used to choose their ideal tax rates.
} 
explore in the next section the reasons behind the large estate tax effects. We show that both the informational and the emotional content of the estate tax treatment matter (a purely clinical information treatment with no emotional component increases support by 50 percent instead of more than doubling it).

A common critique of survey experiments that find large effects on opinion is that one cannot know how these effects impact actual behavior. We try to partially bridge this gap by asking individuals whether they would send a petition to their U.S. Senator asking either to raise or lower the estate tax. We provided a link to Senators' emails and also provided sample messages both for and against raising estate taxes. We then asked if the respondent would send a petition for higher taxes, a petition against higher taxes, or nothing at all.

We report these results in col. (4). The treatment significantly increases the propensity of respondents to say they would petition their U.S. Senator to raise the estate tax (though, not surprisingly, this effect is smaller than the pure opinion question, suggesting attenuation from belief to action). Naturally, we recognize that we must take respondents' word that they will send the email and thus this outcome is not as concrete as, for example, knowing with certainty how they would vote in the next election. At the very least, this result confirms the strong effect of the treatment on views about the estate tax. As mentioned, we probe later on the robustness of this result and offer some thoughts on why it is so different from the income tax. For now we merely note that these large results serve to dismiss a potential explanation of why the income tax results were so small - that there is something inherent in the mTurk experience that mutes respondents' policy responses.

While so far we have focused on policies that affect the well-off, we also asked a series of questions about policies that impact the bottom of the income distribution. While the treatment induces significant but small (less than ten percent of the political gap) effects for the minimum wage (col. 5), it induces no significant increase in support for food stamps or the Earned Income Tax Credit (EITC) (results reported in appendix Table 4). ${ }^{23}$ The results thus suggest a contrast between direct transfer policies such as the EITC and food stamps and indirect transfer policies such as the minimum wage, a theme that will also emerge in some of the follow-up work discussed in next section. ${ }^{24}$

\footnotetext{
${ }^{23}$ In later follow-up work, we asked a small pilot group to write open-ended responses to many of our outcome variables. Many respondents had little familiarity with the EITC (though we always provided a description) so the non-result for that outcome might need to be interpreted more cautiously. No respondent indicated unfamiliarity with food stamps or the minimum wage, however.

${ }^{24}$ There are other possible distinctions between these policies. For example, respondents may have stronger racial stereotypes of food-stamp recipients than they do of minimum-wage workers.
} 


\subsection{Views of government and political involvement}

Columns (6)-(8) of Table 5 reports results on the effect of the treatment on opinions about government. The first question asked respondents: "How much of the time do you think you can trust government in Washington to do what is right?" and we code a respondent as trusting government if she answers "always" or "most of the time" as opposed to "only some of the time" and "never." ${ }^{25}$ Col. (6) reports a large decrease in the share of treatment respondents agreeing that the government can be trusted. The treatment is equal to the entire liberal-conservative gap, but operates in the opposite direction to the other outcomes, in that it makes respondents take the more conservative - and less trusting - view on this question. ${ }^{26}$ Note also that, consistent with the trends noted in the Introduction, the control group has a very low level of trust in government-only about 16 percent are trusting of government, by our definition - and that the contrast of liberals and conservatives about trusting government is fairly small (17 vs. 14.5 percent, see Table 2). The low baseline level of trust in the control group suggests that the treatment effect we observe might in fact understate the true effect experienced by the treatment group, as their ability to express an even lower opinion of government is limited by floor effects.

The second question assesses respondents' preferred scope of government: "Next, think more broadly about the purpose of government. Where would you rate yourself on a scale of 1 to 5 , where 1 means you think the government should do only those things necessary to provide the most basic government functions, and 5 means you think the government should take active steps in every area it can to try and improve the lives of its citizens?" 27 Intriguingly, the treatment significantly moves people toward wanting a more active government (col. 7). Providing information about the growth of inequality and the ability of the government to raise taxes and redistribute have complicated effects on views of government. It appears to make respondents see more areas of society where government intervention may be needed but simultaneously make them trust government less. We return to these results linking trust in government to preferences on government scope in Section 4.2.1.

Finally, as shown in col. (8), the treatment has almost no effect on respondents' planned

\footnotetext{
${ }^{25}$ This question is taken from ANES http://www.electionstudies.org/nesguide/toptable/ tab5a_1.htm.

${ }^{26}$ We say that being less trusting of government is the "conservative" view because in our data as well as GSS data from the same time period, conservatives indeed report lower trust in government. These tendencies are sensitive to the party in power (e.g., in the GSS, during the George W. Bush administration, conservatives were more trusting of the executive branch than were liberals).

${ }^{27}$ This question comes from Gallup.
} 
voting choice for the 2012 Presidential elections (recall that the omnibus-treatment surveys were completed before the November 2012 election). There is at best a marginal effect in the direction of supporting President Obama. This result is consistent with the relatively mild policy effects overall. The treatment may simultaneously make individuals want the more redistributive policies of the Democratic party and distrust the party in power (the Democrats under Obama, at least in the executive branch and the Senate). ${ }^{28}$

\subsection{Robustness checks}

Persistence of effects. Before mTurk, recontacting survey respondents was onerous, and thus few papers were able to test the duration of effects from informational survey experiments. None of the papers cited in the Introduction on the effect of information on redistributive preferences follows up with respondents to measure the duration of the effects. ${ }^{29}$

The evidence from the few papers that do test persistence is not encouraging. Luskin, Fishkin, and Jowell (2002) find that even the immediate effects of an extreme interventionin which British participants spent a weekend with experts, with the goal of debunking misconceptions about crime and prison policy — do not persist ten months later. Indeed, in a similarly intense intervention focused on issues related to campaign finance, Druckman and Nelson (2003) find that their results dissipate within ten days. While not a survey experiment per se, Gerber et al. (2011) use variation in the location of campaign television advertising to show that persuasive effects are strong the week the ad airs but have little persistence beyond the first week. Perhaps closest to our methodology, Lecheler and Vreese (2011) sample Dutch respondents to test for the effect of informational treatments on opinions about economic aid to Bulgaria and Romania; while the treatment effect persisted after one week, it was insignificant after two.

The flexibility of the mTurk platform offers the possibility of resurveying participants months after the original survey. In the third round of the omnibus survey, we attempted to recontact respondents one month after taking the survey. Out of 1039 respondents who completed the original survey, 145 (14 percent) completed the follow-up survey. The followup survey asked most of the outcome questions in the original survey, but did not include the informational treatment.

\footnotetext{
${ }^{28}$ In the interest of space, there are some outcome variables we relegate to the Appendix. The full set of all results from the omnibus survey are found in Appendix Tables 4, 5, and 6 .

${ }^{29}$ In their review of the use of survey experiments, Gaines, Kuklinski, and Quirk (2007) name measuring duration effects as their top recommendation for future work in the area.
} 
With a relatively low take-up rate, a concern is that follow-up respondents are differentially selected. Appendix Table 7 suggests that while some selection takes place (by age, marital status and employment status) the most important variables in terms of predicting preferences (support of Obama and overall liberal-versus-conservative policy views) show no differential selection into the follow-up sample. Nor does initial treatment status predict take-up and thus we have a roughly equal number of control and treatment observations in the follow-up sample.

We compare the original results for these 145 observations to their responses one month later for selected outcomes in Table 6 and for all other outcomes in Appendix Tables 8 and 9. As only some outcomes show a substantial initial treatment effect for the $N=145$ subsample, it is not feasible to have meaningful tests of persistence for all outcomes.

Cols. (1) and (2) show that our most robust outcome result from the original surveysupport for increasing the estate tax - is strongly persistent. In absolute terms, 58 percent of the effect size remains one month later, more than doubling the share who support the policy. And the effect one month later remains highly statistically significant.

Cols. (3) and (4) show similarly strong results for views on the proper scope of government. The follow-up result in col. (4) actually shows an increase in the point-estimate, though it is within the confidence interval of the result in col. (3).

Cols. (5) and (6) show that the initial treatment effect on "trust in government" is slightly larger than for the full sample, with a negative, but now insignificant effect persisting one month later.

Unfortunately, as cols. (7) and (8) show, one of the main outcome variables from the omnibus survey — concern for inequality - yields an initial treatment effect of essentially zero for the subsample, and thus testing for persistence is not particularly meaningful. Given that our initial treatment often had small effects for the entire sample, it is not surprising that only some outcomes yield substantial initial treatment effects for the subsample. We thus relegate the follow-up results for all these outcomes to Appendix Tables 8 and 9.

Overall, the follow-up analysis shows, once again, that the estate tax emerges as the policy most robustly and significantly affected by our omnibus treatment.

Bounding the effects of differential attrition. While we showed in Table 3 that, conditional on finishing the survey, assignment to the treatment appears as good as random, here we further probe the potential effects of attrition. To conduct a bounding exercise, we assume either that (1) attriters would have all had the average "liberal" view for each outcome; or 
(2) they would have had the average "conservative" view for each outcome. Given that attrition does not actually vary by political views (see Appendix Table 2) but outcome values vary substantially by political views (see Table 2), this test should provide generous upper bounds on the potential effects of attrition. The results in Appendix Table 10 shows that no signs flip for any of our main outcome variables under either the conservative (columns labeled "C") or liberal (columns labeled "L") attrition assumptions.

Next, we examine how the level of differential attrition affects our results: do our results only hold in survey rounds with high differential attrition between the control and treatment group? The first three rounds of the omnibus surveys had very similar differential attrition rates (between 12 and 16 percent), whereas the fourth had a substantially lower attrition rate (five percent). Appendix Tables 11 and 12 show that our main results on concern for inequality, support for the estate tax, and trust in government are robust and at times stronger for the low-differential-attrition round, the round where we expect our identification assumptions to be most robust. As before, the "non-results" for other outcomes remain (not shown). ${ }^{30}$ In Section 4, we analyze follow-up surveys where the treatment is much shorter and where there is virtually no differential attrition by treatment status (see Appendix Table 3). The fact that these follow-up surveys largely confirm our omnibus treatment results provides further reassurance that differential attrition is not driving our results.

Robustness across rounds. As our rounds took place at different dates with different stories dominating the news cycle, we might worry that the treatment effects are being driven by a single round. We verified that dropping rounds one by one does not change the sign or significance of the main results.

Survey fatigue. Finally, "survey fatigue" would not seem to explain our results. For example, the question "is inequality a serious problem" comes before top tax rates, which precedes the estate tax question, our strongest effect. Therefore, there is no monotonic relationship between the strength of the treatment effect and the order of the outcome variables.

Experimenter demand effects. A potential bias that is more difficult to measure is differential experimenter demand effects - perhaps it is the case that a variable such as "inequality is a serious problem" is more susceptible to demand effects than concrete policy questions

\footnotetext{
30
}

In our context, the only observable variable that is correlated with differential attrition between control and treatment is the round of the experiment. Hence, our comparison across rounds is the simplest and most transparent non-parametric form of Dinardo-Fortin-Lemieux (DFL) reweighting. 
such as "preferred top income tax rates." An indirect test is to examine gender differences by outcome variable, as women appear more likely to give the "desired" answer (see, e.g., Bernardi, 2006, Dalton and Ortegren, 2011 and citations therein). We find very small gender differences overall, and no pattern whereby they are larger for women for the "first-stage" outcomes (results available upon request). Recent work argues that demand effects are likely muted with internet surveys (see, e.g., Kreuter, Presser, and Tourangeau, 2008 and Gelder, Bretveld, and Roeleveld, 2010).

\section{Understanding our Results with Follow-up Surveys}

The follow-up surveys share the following structure. While we repeated most of the outcome questions used in the omnibus surveys, there are some differences (based on input from referees and others). For example, we ask respondents to report whether "poverty is a serious problem," as well as rank "private charity" and "education" in a list of tools to address inequality (so as to gauge whether respondents react to the treatments by turning to options - some non-governmental — more often advocated by political conservatives). ${ }^{31} \mathrm{We}$ also replace the question about the EITC (which we feared might not be sufficiently familiar to respondents) with a general question about "aid to the poor" and a specific question about public housing, while retaining the minimum wage and food stamp questions.

For the sake of completeness, we used the same battery of outcome questions for all followup surveys, even when certain follow-up treatments were unlikely to affect a given outcome. For the sake of brevity and exposition, we only discuss in the main text those outcomes that are relevant to a given treatment, but all other outcomes are reported in the Appendix for each treatment. Importantly, in this section, we use data solely from the follow-up surveys because the control groups in the omnibus survey and the follow-up surveys are not directly comparable, and because the wording of some of the questions has changed.

Section 4.1 explores why the estate tax appears to be an anomaly, first verifying that the effect is robust to changes in presentation and then measuring the pure informational impact of our treatment. Section 4.2 explores potential mechanisms for why most other policies are more impervious to informational interventions.

\footnotetext{
${ }^{31}$ For example, McCall and Kenworthy (2009) argue that Americans care about inequality but prefer policy levers such as education to combat it, not income redistribution. In our data, (control group) conservatives are indeed more likely to rank education and private charity above tools that more directly involve government redistribution.
} 


\subsection{Why are views about the estate tax so elastic to information?}

In this section, we present two types of follow-up analysis on the estate tax. First, we verify whether the estate tax treatment effect - an outlier among the policy outcomes analyzed in the previous section - is truly robust. After showing that it withstands several significant modifications of the treatment, we then present evidence as to why this effect is so strong. Our view is that misinformation about the estate tax is far greater than for the other policies we surveyed, such that the informational treatment has an especially large impact. ${ }^{32}$

Verifying the large estate tax effects. Recall that the omnibus treatment includes not only information about the incidence of the estate tax, but several other components as well (e.g., the interactive feature showing respondents' place in the income distribution, among the others we described in Section 1). To gauge the sensitivity of the estate tax effect to this additional information, we redid the experiment with a treatment that only included the slide on the estate tax. Furthermore, the original estate tax treatment shows a picture of a mansion and notes that the estate tax can help "level the playing field" (see Appendix Figure 4). We thus formulated a treatment that decreased the emotional impact of the estate-tax treatment and that only mentions the incidence in dry, factual terms (see Appendix Figure $6)$. We call the first version the "emotional estate tax treatment" and the second the "neutral estate tax treatment." Again, neither of these treatments contains the other, non-estate-tax components of the omnibus treatment.

Table 7 displays results for the key outcome variables. In contrast to the omnibus treatment, the "emotional" estate tax treatment has no effect on views about whether inequality is a problem, whether it has increased, or whether the rich are "deserving" (cols. 1, 2 and 3). The "neutral" treatment appears to have countervailing effects: increasing concern for inequality (though this effect is much smaller than that of the omnibus treatment) while decreasing the sense that inequality has increased. These much weaker effects are not surprising because these two treatments provide no information about income inequality or its trends.

However, col. (4) shows that the effect of even these more limited treatments on opinions about the estate tax remains strong. The point-estimate for the "emotional treatment" is

\footnotetext{
${ }^{32}$ Theoretically, the prospect for upward mobility mechanism of Benabou and Ok (2001) that limits the desire for redistribution might become irrelevant when respondents realize that only 1 decedent out of 1000 pays the estate tax. Following Alesina and Angeletos (2005)'s theory, respondents might also support the estate tax on the very wealthy as they realize that receiving a very large inheritance is due entirely to luck and not effort of the inheritor.
} 
nearly as large as that of the omnibus treatment (0.289 versus 0.357$)$. The "neutral" effect is smaller (0.109), though both in absolute and scaled terms swamps any policy effect (excluding the estate tax itself) associated with the omnibus treatment. Recall that the omnibus treatment provided extensive interactive and personalized information on income inequality and income tax rates and typically produced scaled effects on the income tax outcomes of ten percent. The "neutral" estate tax treatment consisted of a total of four sentences but nonetheless produced a scaled effect on the estate tax four times as large (40.8 percent of the liberal-conservative gap). This stark contrast highlights how much more elastic to information views about the estate tax are than those about the income tax and other policies.

As shown in col. (5), both treatments make respondents more likely to say they will petition their Senator (scaled effects greater than 0.2 ), but this effect is not statistically significant. The significant effect with the omnibus treatment suggests that the background information on growing inequality might be required to induce more respondents to connect their policy views with political activism. Col. (6) shows that the effect on trust in government is negative (as in the omnibus treatment) but not significant. ${ }^{33}$

Why are estate tax preferences so malleable to information? At first, we attributed this finding to our treatment having larger effects for topics that held little ex-ante salience for our respondents. However, recent polling data suggests the estate tax is very salient to respondents - in 2010, Gallup respondents named averting an increase in the estate tax as their top priority for the lame-duck session of Congress, above extending unemployment benefits and the Bush income tax cuts. ${ }^{34}$ Moreover, there were no more "missing" responses on the estate tax question than on other policies questions in the control group, further evidence that the estate tax is not an obscure issue to respondents in our sample.

A more promising explanation is that while respondents may view the estate tax as a salient issue, they may hold misinformed views on the topic. Indeed, as documented by Slemrod (2006), 82 percent of respondents favor estate tax repeal but 49 percent of respondents believe that most families have to pay it, compared to 31 percent who believe only a few families have to pay, and 20 percent who admit to not knowing. In contrast, the public appears much better informed about policies such as the minimum wage or the individual

\footnotetext{
${ }^{33}$ Given that the omnibus treatment had, at best, small effects on income tax and transfer policies, it is not surprising that the estate-tax-only treatments do not produce consistently significant effects on these outcomes either (Appendix Table 13 and 14).

${ }^{34}$ See http://www.gallup.com/poll/144899/Tax-Issues-Rank-Top-Priority-Lame-DuckCongress . aspx.
} 
income tax. ${ }^{35}$ As a result, providing basic information on how the current federal estate tax is limited to the very wealthiest families might serve as a large informational shock.

We directly tested this hypothesis by adding a question on the incidence of the estate tax to the follow-up surveys. Respondents were asked to choose the share of decedents subject to the estate tax from among the following percentage options: less then 1, 1, 10, 20, 40, 60, and 100 percent. If anything, the greater detail offered for choices below twenty percent would seem to tip-off respondents that the answer is a small number, but only 12 percent of control group respondents answered correctly (random guessing would be correct 14 percent of the time) and accuracy varied substantially by political orientation (16 percent of liberals versus 6 percent of conservatives).

Col. (7) of Table 7 shows the effect of the two estate tax treatments on respondents' likelihood to choose the correct response. Both treatments roughly triple the likelihood of answering correctly, strongly suggesting that information is a key mechanism behind the large effects of the omnibus treatment. ${ }^{36}$ Importantly, misinformation is not a sufficient condition for an informational treatment to have large effects. As noted earlier, Kuklinski et al. (2003) found that correcting substantially misinformed views on welfare was not sufficient to change respondents' support, though perhaps the lack of elasticity is due to the racial stereotypes the world "welfare" brings to mind (Gilens, 1996). The estate tax may be one of a few issues on which voters are highly misinformed but their ignorance is not linked to racial or other stereotypes. In any case, extrapolating from the estate tax effects would give vastly biased views of the ability of information to move other redistributive policy preferences, as we saw in the previous section and as we further document below.

\footnotetext{
${ }^{35} \mathrm{~A}$ recent Pew survey shows that $73 \%$ of respondents could identify the correct current minimum wage (see http://www . people-press.org/2014/10/02/from-isis-to-unemployment-what-doamericans-know/). For the individual income tax, we asked respondents in an earlier pilot to give us their best guess of actual average tax rates by income brackets. On average, respondents came fairly close to actual tax rates both in level and in terms of progressivity. For example, for top bracket taxpayers with income above $\$ 379,150$, they guessed a tax rate of $29.1 \%$ on average when the actual tax rate based on 2012 IRS statistics is $26.4 \%$. Consistent with these results, Fujii and Hawley (1988) find that, on average, survey respondents perceive fairly accurately the marginal tax rates they face.

${ }^{36}$ Our results offer experimental support for the observational regression analysis presented by Slemrod (2006) showing that support for the estate tax is lower when respondents believe that most families have to pay it.
} 


\subsection{Exploring the limited treatment effects on policy preferences}

We explore three potential explanations for why the omnibus treatment had small policypreference effects (aside from the estate tax). Of course, other explanations may exist, so one should not not view our analysis of the mechanisms behind the policy "non-results" as definitive or exhaustive.

\subsubsection{Does government distrust explain limited treatment effects?}

As documented in Section 3, the omnibus treatment significantly reduces trust in government. It is perhaps not surprising that an informational treatment emphasizing a dramatic increase in income inequality would lower respondents' view of government. But, to our knowledge, it remains an open question whether lowering trust in government has a causal effect on policy preferences. This question has perhaps never been more relevant in the U.S. context, given that Americans' trust in government is at historically low levels, as noted in the Introduction.

To test the causal effect of trust in government on policy preferences, we devised a treatment that lowers trust but does not affect views on other factors that might affect policy preferences. This task is not easy - as we saw with the omnibus treatment, information about inequality reduces trust in government, but also increases concern about inequality, meaning the omnibus treatment effects on the policy outcomes are the joint effect of increasing concern about inequality (which we hypothesize would increase support for government action) and reducing trust in government (which we hypothesize would decrease it).

We began by collecting a small pilot study $(N \approx 150)$ on mTurk where we asked people to answer our basic trust question (how often they can trust the government to do what is right) but then to explain why they answered the way they did. Note that they answer this question directly after answering the demographic questions and are thus not being primed to think about inequality. There is no "treatment" in this pilot - we are merely asking people to explain their opinion. The pilot group cast light into why trust in government is currently so low. Respondents feel politicians are out to enrich themselves and their wealthiest donors. "Money," "corporations" and "special interests" are some of the most commonly used words and phrases in these answers, as Appendix Figure 7 shows. The detailed descriptions given by respondents allowed us to develop primes we thought could lower trust in government without necessarily affecting other factors that would have a direct effect on policy preferences.

Our treatment consists of several multiple-choice questions that induce respondents to reflect on aspects of government they dislike. For example, we asked if they agree that 
"Politicians in Washington work to enrich themselves and their largest contributors, instead of working for the benefit of the majority of citizens" (90 percent do). We also showed them results from a ranking of OECD countries in terms of government transparency in which the US was categorized in the bottom quartile (see Appendix Figure 8 for a screenshot and Appendix A for the full description).

Results. Table 8 shows the results of this treatment on a variety of outcomes. Col. (1) shows that the first stage "works" - the treatment significantly decreases respondents' stated trust in government, by 5.8 percentage points in absolute terms or 1.78 times the liberalconservative gap on this question. This effect is slightly larger than the effect of the omnibus treatment (roughly 1.1 times the liberal-conservative gap), not surprising given that the goal of this treatment was to lower trust. As we saw with the omnibus treatment, respondents appear to separate how much they trust the government with what they view as its proper scope, as the treatment has no effect on that outcome (col. 2). The treatment makes them more likely to view the government as wasteful, but the effect is not significant (col. 3).

Cols. (4) through (6) suggest that we were largely successful in devising a treatment that isolates the effect of trust, at least with respect to our standard questions on income inequality and poverty. There is a marginal effect of the treatment in increasing concern about inequality, but no effect on the sense inequality has increased or the sense that poverty is a problem. The results from the omnibus treatment suggest that, if anything, the uptick in concern about inequality should have a mildly positive effect on treatment respondents' tendency to support redistributive policies. As such, it would mask the effects of decreasing trust in government on support for redistributive policies, which we hypothesize to be negative.

Table 9 displays those results. The treatment decreases support for a tax on millionaires, though this result is not quite statistically significant (when the continuous top tax rate is used instead as the outcome, the coefficient is positive but essentially zero, see Appendix Tables 15 and 16 for this and other results not discussed in the main text). While stated support for expanding the estate tax is essentially unchanged by the treatment, the stated willingness to petition for its expansion is significantly reduced (a scaled effect of 0.588 ).

The estimated effects of trust on support for transfer programs to the poor are much less equivocal. While support for the minimum wage is unaffected (col. 4), treatment respondents significantly reduce their support for "aid to the poor" generally (col. 5), and food stamps and public housing specifically (cols. 6 and 7). Finally, some interesting results emerge when 
respondents are asked to rank a list of options for addressing inequality (a higher number here means more support). Col. (8) shows the treatment causes respondents to elevate a non-governmental solution to inequality - private charity, which, as noted at the beginning of the Section, is generally preferred by more conservative respondents.

Discussion. Decreasing respondents' trust in government appears to have a strong, negative effect on support for direct government transfers. As further support for the trust mechanism, the treatment has no effect on support for the minimum wage, which is an indirect transfer that does not involve the government receiving and redistributing tax dollars. Recall also that the omnibus treatment failed to increase support for direct transfer programs (the EITC and food stamps) but did increase support for the minimum wage. As Table 9 shows that support for the minimum wage appears unaffected by changes in trust, trust emerges as a plausible mediating variable that can explain the pattern of results for the omnibus treatment.

\subsubsection{Emotional versus factual appeals}

There is a long psychology literature that suggests that for many issues, emotional appeals produce larger changes in attitudes than more factual presentations. ${ }^{37}$ Indeed, the estate tax follow-up experiment described in Section 4.1 showed that the neutral treatment had a smaller effect than the emotional treatment. While our omnibus treatment provided extensive interactive and personalized information, it was mostly numeric in nature, which may have limited its ability to move policy preferences. Similarly, the focus on the "top one percent" might be less effective than focusing more intensely on the bottom of the distribution.

To test this idea, we developed a treatment meant to create empathy between the respondent and low-income families. Again, the treatment was personalized and interactive. For example, we asked respondents to "[t]hink about a family of $X_{1}$ with $X_{2}$ parent(s) working full time... and $X_{3}$ kids.... What would be the minimal monthly expenses that such a family would have to make to afford living where you live?" The values $X_{1}, X_{2}$, and $X_{3}$ were interactively matched to the household composition that the respondent earlier gave in the demographic module at the start of the survey. The respondent then entered dollar amounts for monthly rent, utilities, transportation, food, and expenses related to children. We then showed them how the budget they devised compared with the income at the poverty line (based on the respondents' household size), emphasizing to them that the budget did not

\footnotetext{
${ }^{37}$ See, e.g., Edwards (1990), Rosselli, Skelly, and Mackie (1995), Loef, Antonides, and Raaij (2001), Huddy and Gunnthorsdottir (2000), and citations therein.
} 
even include items such as health care, clothing, furniture, and costs related to schooling (see the Appendix for a complete description of the treatment and Appendix Figure 9 for a screenshot). ${ }^{38}$ The slides with this information also included photos of low-income families.

Results. Overall, the results track very closely to those from the original omnibus treatment. We obtain large "first stage" effects on concern for poverty and inequality, but little movement on policy preferences.

Table 10 presents the key outcomes. The treatment has significant effects on concern about inequality (col. 1), and, not surprisingly, large effects on whether poverty is a serious problem (equal to over 30 percent of the political gap for this outcome). ${ }^{39}$ However, just like the omnibus treatment, this follow-up "emotional" treatment has limited effect on policy preferences. Of the four poverty-policy questions we asked, only two exhibit a marginally significant treatment effect (food stamps and aid to the poor, and even then just below 8 percent of the political gap). Similar to the omnibus treatment, this follow-up treatment reduces trust in government, though the effect is smaller and not significant. ${ }^{40}$

Discussion. As readers can verify by taking the surveys themselves, the omnibus treatment and this "emotional" follow-up are very different in spirit. The omnibus treatment focused largely on the top one percent and was more factual in nature, whereas the followup treatment focused on the disadvantaged and sought to create empathy both with our "put yourselves in their shoes" exercise as well as photographs of low-income families.

Despite these stark differences, the results are very similar. It is relatively easy for treatments to affect how much individuals are "concerned" with any issue, but much harder to increase their support for policies that would seem directly related to addressing said issues. Our final follow-up survey attempts to make the connection to policy measures more explicit.

\footnotetext{
${ }^{38}$ The large majority (76 percent) devise a budget in excess of the income at the poverty line for a household of their type.

${ }^{39}$ As detailed in Appendix Table 17, the treatment increased the likelihood of correctly choosing the actual poverty rate from multiple choices, though, because many control respondents overestimated the poverty rate, it did not on net increase their estimate of the poverty rate. The fact that the treatment had such a large effect on perceiving poverty as a "very serious problem" likely works through the intensive margin: perhaps through the creation of empathy, the treatment highlights how difficult it would be to manage with limited income.

${ }^{40}$ The treatment had very small but positive effects on taxes on the well-off, always well below ten percent of the political gap and not significant. See Appendix Tables 17 and 18 for these and all other outcomes not displayed in Table 10 .
} 


\subsubsection{Connecting "concerns" with policy measures}

Bartels (2005) documents the seemingly odd result that even though the individuals in his 2002 sample were worried about inequality and aware that the tax cuts proposed by the Bush Administration in 2001 favored the wealthy, they still supported them by a large margin. He concludes that "Americans support tax cuts not because they are indifferent to economic inequality, but because they largely fail to connect inequality and public policy."

We directly test this notion - that respondents do not connect their "concerns" with policies meant to address them-in our final follow-up survey. In this version, we largely repeat the low-income "emotional" treatment described in Section 4.2.2, but also add slides showing how current government programs help these households. First, after entering in the expenses in the budget exercise, the treatment describes a family earning one full-time full-year minimum-wage income, making a salient connection between the level of the minimum wage and family income at the bottom of the income distribution. Second, respondents are told that "The food stamps program helps many low income families, such as those earning only one minimum wage. It provides $\$ 150 /$ month per person to help with food expenses." Hence, the connection between poverty and a government program is made explicit. Appendix Figure 10 provides a screenshot.

Results. We repeat the results for the key outcome variables in Table 11. The "first-stage" effects of this treatment are smaller and not significant. It is not surprising that we do not see much movement in variables related to inequality, since the treatment did not provide any direct information on the topic. Despite the focus on the situation of a low-income household, treatment respondents do not view poverty as a more serious problem. We speculate that emphasizing the efficacy of a government poverty program might have the effect of making poverty and inequality seem less severe.

Despite the somewhat smaller first-stage effects, the effects on our policy outcomes are consistently positive and significant. Support rises for the minimum wage (col. 3), aid to the poor (col. 4), food stamps (col. 5), and public housing (col. 6). The effect on "aid to the poor" is positive but not significant. It should be noted, however, that with the exception of the minimum wage, these effects are still relatively small (roughly about ten to fifteen percent of the political gap). It is also the case that the treatment does not consistently increase support for actually sending money to Washington to pay for these policies: the effects on income and estate taxes for the well-off are mixed (see Appendix Tables 19 and 20). 
However, it does appear that the interaction of the empathic portrayal of low-income families along with information emphasizing the efficacy of a transfer program has a meaningful effect on the policies respondents support. Col. (7) suggests that, in contrast to the trust treatment, this treatment reduces the relative attractiveness of the non-governmental solution to inequality: private charity. Finally, col. (8) shows that there is no significant effect of the treatment on trust in government, though the point-estimate is negative.

Discussion. While this treatment indeed moved policy preferences, it is worth noting its highly explicit nature. After completing an exercise where they contemplated the budget constraints of a low-income family, respondents were shown in concrete terms how a government program helps such a household make ends meet. Even then, while support for many poverty-related programs significantly increased, the largest effect remains the minimum wage, an indirect transfer program. Moreover, the treatment does not have a consistent effect in terms of inducing treatment participants to desire higher taxes (even if only on the wealthy) to pay for these programs.

Taken together, the results from these three follow-up surveys suggest the difficulty in moving most policy preferences. While concern for an issue is highly elastic to information, translating this concern into a change in policy preference appears very difficult, with the consistent exception of the estate tax.

\section{Conclusion}

The standard median-voter model predicts that support for redistribution should increase with income inequality, yet there has been little evidence of greater demand for redistribution over the past thirty years in the United States - despite historic increases in income concentration. A possible explanation is that people are unaware of the increase in inequality, such that greater information would substantially move redistributive preferences. We gather over 10,000 observations using Amazon's Mechanical Turk to conduct a series of survey experiments to extensively explore this hypothesis.

Our results suggest that, generally, greater information can increase respondents' sense of concern about an issue, but not necessarily their support for policies that might ameliorate it. Information about income inequality and poverty has only a limited (and typically statistically insignificant) tendency to increase support for higher income taxes on the well-off or transfer programs for the disadvantaged. 
We present evidence that extreme distrust of government appears to explain part of this null effect. First, trust in government is very low in our sample, as it currently is among Americans more generally. Second, many of our treatments appear to further reduce this already low level of trust. Third, and most novel relative to the literature, we show that decreasing trust has a causal effect on diminishing support for redistribution. We develop a prime that reduces trust in government without significantly moving respondents' concern for inequality and poverty: respondents exposed to this prime significantly reduce their support for programs that involve the government directly redistributing tax dollars, while increasing their support for non-governmental solutions such as private charity.

Only when we explicitly show individuals the concrete effects of government poverty policies do we observe consistent, statistically significant increases in support for such policies. ${ }^{41}$ Even so, such effects are small, and are largest for indirect transfer programs such as the minimum wage that do not involve the government collecting and redistributing tax dollars.

Future work might further probe the connection between government trust and policy preferences. Underlying mistrust might help to explain the reluctance to support policies that would seem to be in the majority's self-interest. Relatedly, distrust could explain why minimum wage increases typically enjoy 70-80 percent support in surveys. Many economists assume that respondents simply misunderstand the incidence of the minimum wage. Instead, it might be the case that they view the minimum wage as imperfect, but better than other redistributive policies that involve sending money to Washington. ${ }^{42}$ In future work, it would be valuable to test whether treatments that increase trust in the government also increase support for redistributive policies.

As we extensively document, the estate tax is the exception to the generally small effects of information on policy: even a four-sentence description providing information on its incidence significantly increases support for the policy. At least part of this effect appears due to vast misinformation - many respondents both in our survey and past work on the estate tax believe a majority of families are subject to it, whereas the actual share is 0.1 percent.

It remains an open question if misinformation fully explains the difference. For example, Americans might view the moral claims to inheritance versus income differently. If the goal of the estate tax is to prevent the self-perpetuation of extreme wealth, then respondents might

\footnotetext{
${ }^{41}$ Future work could also explore how emphasizing the negative aspects of redistribution, such as reduced labor supply, could affect preferences for redistribution.

${ }^{42}$ Notably, voters in several conservative states passed minimum wage hikes in the 2014 midterm elections, consistent with their not viewing the minimum wage as a "government program."
} 
still support it even if, say, the government merely burns the money it collects. Therefore, low levels of trust in government may not inhibit support for the estate tax as much as for other policies where efficiency is a more salient goal. Independent of the origin of the treatment effect, the large elasticity of support for the estate tax in response to basic information that we and past work have documented is highly policy-relevant, given the recent rise in inheritance flows in many developed countries. ${ }^{43}$

Randomized online surveys are a powerful and convenient tool for studying the effects of information treatments on attitudes and behaviors, one we imagine can be used to extend the results we have documented. The tool is powerful because it can reach large samples of U.S. residents (in the thousands) at fairly low cost (\$1-\$2 per respondent). It is convenient because, using widely available software, online surveys are now very easy to design. Hence, it becomes more feasible to explore mechanisms behind results. For example, we were able to easily design companion experiments to test mechanisms potentially underlying the effects in our original, omnibus treatment. Therefore, in contrast to field experiments which are very costly to set-up and replicate, online survey experiments lend themselves naturally to conducting series of experiments where results from an initial experiment lead to new experiments to cast light on potential mechanisms.

Such flexibility will allow researchers to gain a more nuanced understanding of redistributive preferences. While projections are by nature uncertain, the U.S. government is expected to face a long-run fiscal imbalance, largely due to the aging of the population and rising health care costs. ${ }^{44}$ European countries face similar challenges. The distributional effects of any future fiscal rebalancing - raising taxes, cutting spending, or both - will depend in large part on voters' redistributive preferences, how strongly they hold them, and whether and how they act on them. As such, these questions are of first-order importance in public economics. We believe that the methodology we employed in this paper can be used in future research to better understand how individuals' redistributive preferences are formed and shaped.

\footnotetext{
${ }^{43}$ See Piketty (2014), Ch. 11. Unfortunately, data limitations make it difficult to know whether this trend applies specifically to the United States.

${ }^{44}$ See, e.g., the Congressional Budget Office's 2014 long-run budget projections (www.cbo.gov/ publication/45471).
} 


\section{References}

Alesina, A. and G.-M. Angeletos (2005). "Fairness and redistribution." American Economic Review, pp. 960-980.

Alesina, A. and E. L. Ferrara (2005). "Preferences for redistribution in the land of opportunities." Journal of Public Economics 89(5 6), pp. 897 -931.

Alesina, A. F. and P. Giuliano (2011). "Preferences for Redistribution." Handbook of Social Economics, Vol. 1A. Ed. by M. O. J. Jess BenhabiB and A. Bisin. NorthHolland.

Amir, O., D. Rand, and Y. K. GaL (2012). "Economic games on the internet: The effect of $\$ 1$ stakes." PloS ONE 7(2), e31461.

BARTELs, L. M. (2009). "Economic inequality and political representation." The Unsustainable American State. Ed. by L. JACOBS and D. KInG. Oxford University Press, pp. 167196.

BARTELs, L. (2005). "Homer gets a tax cut: Inequality and public policy in the American mind." Perspectives on Politics 3(01), pp. 15-31.

Benabou, R. and E. OK (2001). "Social mobility and the demand for redistribution: The POUM hypothesis." Quarterly Journal of Economics 116(2), pp. 447-487.

Bernardi, R. A. (2006). "Associations between Hofstedes cultural constructs and social desirability response bias." Journal of Business Ethics 65(1), pp. 43-53.

BRADER, T. (2005). "Striking a responsive chord: How political ads motivate and persuade voters by appealing to emotions." American Journal of Political Science 49(2), pp. 388405.

Corneo, G. and H. P. Gruner (2000). "Social Limits to Redistribution." American Economic Review 90(5), pp. 1491-1507.

- (2002). "Individual preferences for political redistribution." Journal of Public Economics 83, pp. 83-107.

Cruces, G., R. Perez-Truglia, and M. Tetaz (2013). "Biased perceptions of income distribution and preferences for redistribution: Evidence from a survey experiment." Journal of Public Economics 98, pp. 100 -112.

Dalton, D. and M. Ortegren (2011). "Gender differences in ethics research: The importance of controlling for the social desirability response bias." Journal of Business Ethics $\mathbf{1 0 3}(1)$, pp. 73-93.

Druckman, J. N. and K. R. Nelson (2003). "Framing and deliberation: How citizens' conversations limit elite influence." American Journal of Political Science 47(4), pp. 729745 .

EDWARDS, K. (1990). "The interplay of affect and cognition in attitude formation and change." Journal of personality and social psychology 59(2), p. 202.

FonG, C. (2001). "Social preferences, self-interest, and the demand for redistribution." Journal of Public Economics 82(2), pp. 225-246.

FujiI, E. and C. HaWley (1988). "On the accuracy of tax perceptions." Review of Economics and Statistics 70(2), pp. 344-347.

Gaines, B. J., J. H. Kuklinski, and P. J. QuiRK (2007). "The logic of the survey experiment reexamined." Political Analysis 15(1), pp. 1-20. 
Gelder, M. M. H. J. van, R. W. Bretveld, and N. Roeleveld (2010). "Web-based Questionnaires: The Future in Epidemiology?" American Journal of Epidemiology 172(11), pp. $1292-1298$.

Gerber, A. S., J. G. Gimpel, D. P. Green, and D. R. Shaw (2011). "How large and longlasting are the persuasive effects of televised campaign ads? Results from a randomized field experiment." American Political Science Review 105(01), pp. 135-150.

Gilens, M. (1996). "Race coding" and White opposition to welfare." American Political Science Review 90, pp. 593-604.

Guillaud, E. (2013). "Preferences for Redistribution: an Empirical Analysis over 33 Countries." Journal of Economic Inequality 11(1), pp. 57-78.

Horton, J., D. Rand, and R. Zeckhauser (2011). "The online laboratory: Conducting experiments in a real labor market." Experimental Economics 14(3), pp. 399-425.

Hoxby, C. and S. Turner (2013). "Expanding college opportunities for high-achieving, low income students." Stanford Institute for Economic Policy Research Discussion Paper (12-014).

Huddy, L. and A. H. Gunnthorsdottir (2000). "The persuasive effects of emotive visual imagery: Superficial manipulation or the product of passionate reason?" Political Psychology 21(4), pp. 745-778.

Kenworthy, L. and L. MCCALL (2008). "Inequality, public opinion and redistribution." Socio-Economic Review 6(1), p. 35.

Kluegel, J. R. and E. R. Smith (1986). Beliefs about Inequality: Americans'Views of what is and what ought to be. New York: Aldine de Gruyter.

Kreuter, F., S. Presser, and R. Tourangeau (2008). "Social Desirability Bias in CATI, IVR, and Web Surveys: The Effects of Mode and Question Sensitivity." Public Opinion Quarterly 72(5), pp. 847-865.

Kuklinski, J., P. Quirk, J. Jerit, D. Schwieder, and R. Rich (2003). "Misinformation and the currency of democratic citizenship." Journal of Politics 62(3), pp. 790-816.

LeCheler, S. and C. H. DE VReEse (2011). "Getting real: The duration of framing effects." Journal of Communication 61(5), pp. 959-983.

Liebman, J. B. and E. F. Luttmer (Aug. 2011). Would People Behave Differently If They Better Understood Social Security? Evidence From a Field Experiment. Working Paper 17287. National Bureau of Economic Research.

Loef, J., G. Antonides, and W. F. RaAiJ (2001). The Effectiveness of Advertising Matching Purchase Motivation. Tech. rep. ERIM Report Series Research in Management.

Luskin, R. C., J. S. Fishkin, and R. Jowell (2002). "Considered opinions: Deliberative polling in Britain." British Journal of Political Science 32(3), pp. 455-487.

Luttmer, E. (2001). "Group loyalty and the taste for redistribution." Journal of Political Economy 109(3), pp. 500-528.

Luttmer, E. and M. Singhal (2011). "Culture, Context, and the Taste for Redistribution." American Economic Journal: Economic Policy 3(1), pp. 157-179.

Margalit, Y. (2013). "Explaining Social Policy Preferences: Evidence from the Great Recession." American Political Science Review, forthcoming.

McCaffery, E. and J. Baron (2006). "Thinking about tax." Psychology, Public Policy, and Law 12(1), p. 106. 
McCall, L. and L. Kenworthy (2009). "Americans' social policy preferences in the era of rising inequality." Perspectives on Politics 7(03), pp. 459-484.

Meltzer, A. and S. Richard (1981). "A rational theory of the size of government." The Journal of Political Economy 89(5), pp. 914-927.

Norton, M. I. and D. Ariely (2011). "Building a better America One wealth quintile at a time." Perspectives on Psychological Science 6(1), pp. 9-12.

Paolacci, G., J. Chandler, and P. Ipeirotis (2010). "Running experiments on Amazon Mechanical Turk." Judgment and Decision Making 5(5), pp. 411-419.

Piketry, T. (1995). "Social Mobility and Redistributive Politics." Quarterly Journal of Economics 110(3), pp. 551-584.

- (2014). Capital in the Twenty-first Century. Harvard University Press.

Piketty, T. and E. SAez (2003). "Income inequality in the United States, 1913-1998." The Quarterly Journal of Economics 118(1), pp. 1-41.

Piketty, T., E. Saez, and S. Stantcheva (2014). "Optimal Taxation of Top Labor Incomes: A Tale of Three Elasticities." American Economic Journal: Economic Policy 6(1), pp. 230-71.

RAND, D. and M. NowAK (2011). "The evolution of antisocial punishment in optional public goods games." Nature Communications 2, p. 434.

Rosselli, F., J. J. Skelly, and D. M. Mackie (1995). "Processing rational and emotional messages: The cognitive and affective mediation of persuasion." Journal of Experimental Social Psychology 31(2), pp. 163-190.

Saez, E. and S. Stantcheva (2013). Generalized Social Marginal Welfare Weights for Optimal Tax Theory. Working Paper 18835. National Bureau of Economic Research.

SAEZ, E. and G. Zucman (Oct. 2014). Wealth Inequality in the United States since 1913: Evidence from Capitalized Income Tax Data. Working Paper 20625. National Bureau of Economic Research.

SapienZA, P. and L. Zingales (2013). "Economic Experts versus Average Americans." The American Economic Review: Papers and Proceedings 103(3), pp. 636-642.

SAVANi, K. and A. RatTAn (2012). "A choice mind-set increases the acceptance and maintenance of wealth inequality." Psychological science 23(7), pp. 796-804.

Senik, C. (2009). Income Distribution and Subjective Happiness: A Survey. Working Paper 96. OECD.

Sides, J. (July 2011). "Stories, Science, and Public Opinions about the Estate Tax."

Singhal, M. (2008). "Quantifying Preferences for redistribution." Harvard University, Working Paper.

Slemrod, J. (2006). "The role of misconceptions in support for regressive tax reform." National Tax Journal 59(1), p. 57.

SuRI, S. and D. WATts (2010). "Cooperation and contagion in networked public goods experiments." PLoS ONE 6(3), e16836.

Weinzierl, M. C. (Dec. 2012). The Promise of Positive Optimal Taxation: A Generalized Theory Calibrated to Survey Evidence on Normative Preferences Explains Puzzling Features of Policy. Working Paper 18599. National Bureau of Economic Research.

YAmAmuRA, E. (2014). "Trust in government and its effect on preferences for income redistribution and perceived tax burden." Economics of Governance 15(1), pp. 71-100. 


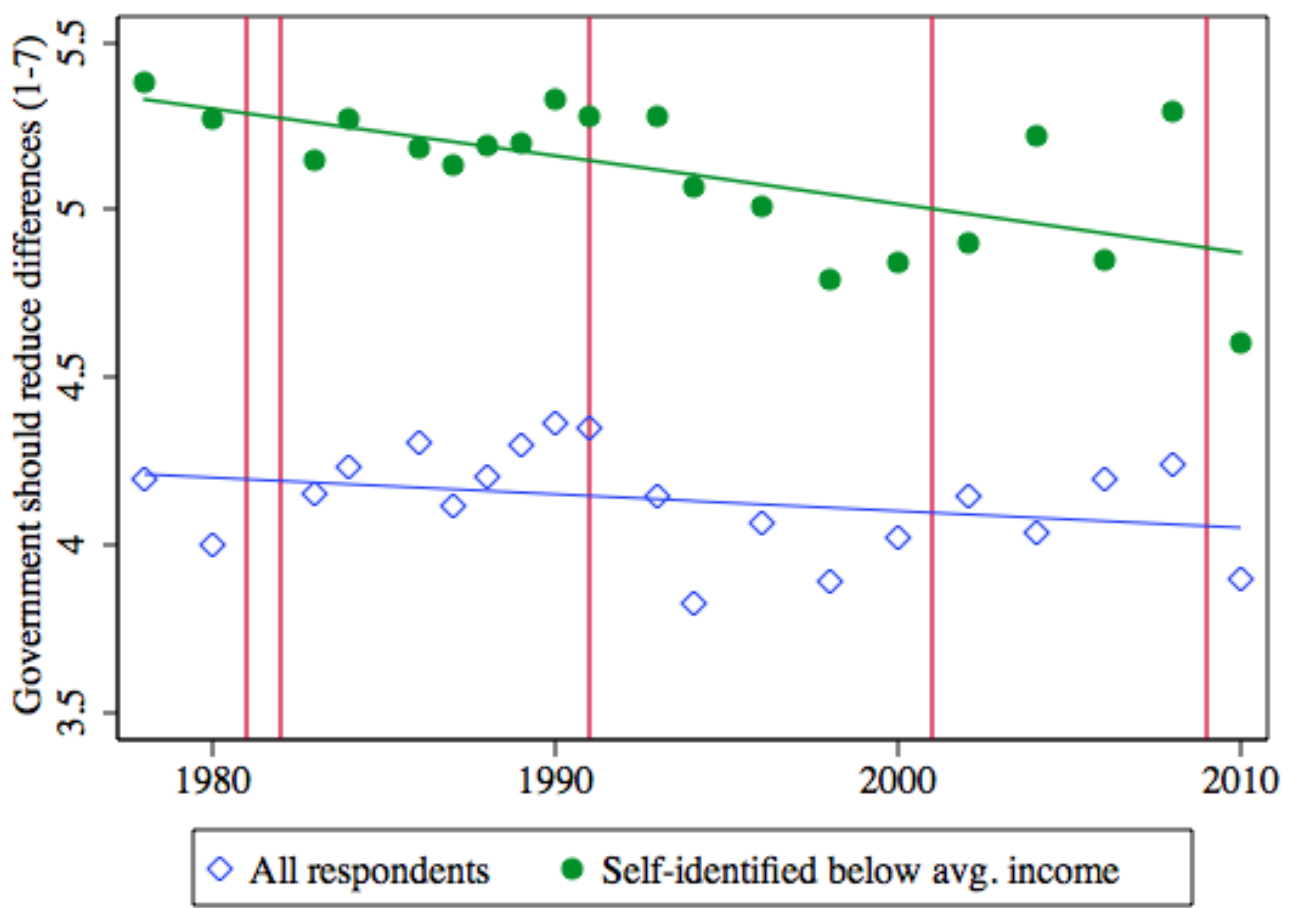

Figure 1: The government should reduce income differences (scale from 1-7, GSS)

This figure depicts responses since 1978 in the US General Social Survey (GSS) on whether the government should reduce income differences. The empty diamond series is for all respondents while the full circle series is for respondents with below average income. Regression fits are depicted for each series. The graph uses the eqwlth variable from the GSS (though subtracts it from eight so that it is increasing in support for redistribution). 
Table 1: Summary statistics and comparison to other polling and online data

\begin{tabular}{lccc}
\hline & $(1)$ & $(2)$ & $(3)$ \\
& mTurk sample & CBS election poll & American Life Panel \\
\hline Male & 0.428 & 0.476 & 0.417 \\
Age & 35.41 & 48.99 & 48.94 \\
White (non-Hisp) & 0.778 & 0.739 & 0.676 \\
Black & 0.0756 & 0.116 & 0.109 \\
Hispanic & 0.0444 & 0.0983 & 0.180 \\
Other racial/ethnic group & 0.0759 & 0.0209 & 0.0410 \\
Employed (full or part) & 0.465 & 0.587 & 0.557 \\
Unemployed & 0.123 & 0.104 & 0.103 \\
Married & 0.397 & 0.594 & 0.608 \\
Has college degree & 0.433 & 0.318 & 0.309 \\
Voted for Obama & 0.675 & 0.555 & 0.559 \\
Political views, cons. (1) to lib. (3) & 2.176 & 1.586 & 1002 \\
\hline Observations & 3741 & 808 & \\
\hline
\end{tabular}

Notes: This table displays summary statistics from our mTurk omnibus surveys in column (1) along with (weighted) averages based on a 2011 CBS news survey in column (2) and RAND's online American Life Panel (ALP) in column (3). We are grateful to Ray Fisman for providing us with summary statistics from the ALP. 
Table 2: Summary statistics for the Control Group, split by Liberals and Conservatives

\begin{tabular}{lccc}
\hline & $(1)$ & $(2)$ & $(3)$ \\
& Liberals & Conservatives & All \\
\hline Male & 0.407 & 0.472 & 0.422 \\
Age & 32.618 & 39.823 & 35.557 \\
White & 0.752 & 0.838 & 0.776 \\
Black & 0.090 & 0.063 & 0.085 \\
Hispanic & 0.039 & 0.027 & 0.037 \\
Asian & 0.090 & 0.053 & 0.078 \\
Married & 0.302 & 0.543 & 0.402 \\
Has college degree & 0.462 & 0.455 & 0.430 \\
Unemployed & 0.140 & 0.076 & 0.121 \\
Not in labor force & 0.093 & 0.208 & 0.144 \\
Voted for Obama in 2008 & 0.914 & 0.303 & 0.674 \\
Inequality has increased & 0.836 & 0.615 & 0.738 \\
Inequality is a very serious problem & 0.414 & 0.129 & 0.285 \\
Top Tax Rate & 34.181 & 23.996 & 30.205 \\
Increase Millionaire Tax & 0.904 & 0.452 & 0.740 \\
Increase Estate Tax & 0.254 & 0.080 & 0.171 \\
Increase min wage & 0.822 & 0.496 & 0.690 \\
Support food stamps & 0.850 & 0.446 & 0.686 \\
Support EITC & 0.722 & 0.418 & 0.611 \\
Trust Govt & 0.171 & 0.148 & 0.158 \\
Scope of Govt is broad & 3.552 & 2.349 & 3.076 \\
Said would petition for higher inc taxes (early rounds only) & 0.288 & 0.118 & 0.238 \\
Send petition for high estate tax & 0.305 & 0.141 & 0.234 \\
Plan to vote democrat 2012 & 0.800 & 0.182 & 0.529 \\
\hline Observations & 821 & 475 & 1976 \\
\hline Notes: This table & & & \\
\hline
\end{tabular}

Notes: This table displays summary statistics based on control respondents from the omnibus surveys, stratified by self-reported liberal vs. conservative status (on a five-point scale, very liberal, liberal, center of the road, conservative, very conservative). Column (1) is for liberals (less than three on the scale) while column (2) is for conservatives (more than three on the scale). Col. (3) shows summary statistics for the entire control group, including the "center of the road" respondents. The complete wording of these survey questions is reported in the Appendix. 
Table 3: Ability of covariates to predict treatment status, conditional on finishing the survey

\begin{tabular}{lcr}
\hline Variable & Coefficient & P-value \\
\hline Voted for Obama in 2008 & 0.003 & 0.856 \\
Age & -0.001 & 0.479 \\
Liberal policy view & 0.002 & 0.751 \\
Household income & 0.005 & 0.109 \\
Married & -0.013 & 0.434 \\
Education & -0.003 & 0.575 \\
Male & 0.013 & 0.447 \\
Black & -0.066 & 0.031 \\
Hispanic & 0.091 & 0.021 \\
Native & -0.043 & 0.201 \\
Employed full time & -0.012 & 0.502 \\
Unemployed & 0.015 & 0.539 \\
Not in labor force & 0.021 & 0.376 \\
Student & -0.027 & 0.235 \\
\hline
\end{tabular}

Notes: For each row, the coefficient and $p$-value are from regressions of the form Assigned to treatment $_{i r}=\alpha+\beta$ Covariate $_{i}+\delta_{r}+\epsilon_{i r}$, where Covariate is listed to the left in the row and $\delta_{r}$ are survey round fixed effects. Those tests are used to detect selective attrition (as treatment respondents are approximately ten percentage points less likely to complete the omnibus survey than are control respondents, see Appendix Table 3). If we regress treatment status jointly on all covariates and survey round fixed effects, we obtain a p-value for joint significance of 0.12.

Table 4: Effect of omnibus treatment on opinions about inequality ("first-stage" outcomes)

\begin{tabular}{|c|c|c|c|c|c|c|}
\hline & \multicolumn{2}{|c|}{ Ineq. v. serious } & \multicolumn{2}{|c|}{ Ineq. increased } & \multicolumn{2}{|c|}{ Rich deserving } \\
\hline & $(1)$ & $(2)$ & $(3)$ & (4) & $(5)$ & (6) \\
\hline Treated & $\begin{array}{c}0.102^{* * *} \\
{[0.0154]}\end{array}$ & $\begin{array}{l}0.104^{* * *} \\
{[0.0144]}\end{array}$ & $\begin{array}{c}0.119^{* * *} \\
{[0.0130]}\end{array}$ & $\begin{array}{c}0.120^{* * *} \\
{[0.0128]}\end{array}$ & $\begin{array}{c}-0.0500^{* * *} \\
{[0.0119]}\end{array}$ & $\begin{array}{c}-0.0526^{* * *} \\
{[0.0114]}\end{array}$ \\
\hline Control mean & 0.285 & 0.285 & 0.738 & 0.738 & 0.180 & 0.180 \\
\hline Scaled Effect & 0.357 & 0.365 & 0.539 & 0.540 & 0.173 & 0.182 \\
\hline Covariates? & No & Yes & No & Yes & No & Yes \\
\hline Obs. & 3703 & 3703 & 3704 & 3704 & 3690 & 3690 \\
\hline
\end{tabular}

Notes: The three outcome variables are binary indicator variables, coded as one if the respondent says that "inequality is a very serious problem," "inequality has increased," and "the rich are deserving of their income," respectively. All regressions have round fixed effects, even those labeled as including "no" covariates. Controls for covariates further include all variables in the randomization table (Table 3), plus state-of-residence fixed effects. "Scaled effect" is the coefficient on Treated divided by the difference between control group liberals and conservatives. The row "Control mean" reports the mean of the outcome variable for the entire control group. ${ }^{*} p<0.1,{ }^{* *} p<0.05,{ }^{* * *} p<0.01$ 
Table 5: Effect of omnibus treatment on policy preferences

\begin{tabular}{|c|c|c|c|c|c|c|c|c|}
\hline & $\frac{\text { Top rate }}{(1)}$ & $\frac{\$ 1 \mathrm{M} \operatorname{tax}}{(2)}$ & $\frac{\text { Estate }}{(3)}$ & $\frac{\text { Petition }}{(4)}$ & $\frac{\text { Min. wage }}{(5)}$ & $\begin{array}{c}\text { Trust } \\
(6)\end{array}$ & $\frac{\text { Scope }}{(7)}$ & $\frac{\text { Dem } 2012}{(8)}$ \\
\hline Treated & $\begin{array}{l}0.931^{*} \\
{[0.549]}\end{array}$ & $\begin{array}{c}0.0502^{* * *} \\
{[0.0126]}\end{array}$ & $\begin{array}{l}0.357^{* * *} \\
{[0.0140]}\end{array}$ & $\begin{array}{c}0.0648^{* * *} \\
{[0.0156]}\end{array}$ & $\begin{array}{l}0.0325^{* *} \\
{[0.0141]}\end{array}$ & $\begin{array}{c}-0.0292^{* *} \\
{[0.0115]} \\
\end{array}$ & $\begin{array}{l}0.132^{* * *} \\
{[0.0339]} \\
\end{array}$ & $\begin{array}{c}0.0152 \\
{[0.0125]} \\
\end{array}$ \\
\hline Control mean & 30.21 & 0.740 & 0.171 & 0.234 & 0.690 & 0.158 & 3.076 & 0.529 \\
\hline Scaled Effect & 0.0914 & 0.111 & 2.043 & 0.394 & 0.0995 & 1.250 & 0.110 & 0.0246 \\
\hline Obs. & 3741 & 3704 & 3673 & 3060 & 3690 & 3702 & 3704 & 3703 \\
\hline
\end{tabular}

Notes: "Top rate" is continuous (respondents' preferred average tax rate (in percent) on the richest one percent). "Scope" is also continuous (a 1-5 variable, increasing in the preferred scope of government activities). All other variables are binary. "\$1M tax" and "Estate" indicate the respondent wants income taxes on millionaires and the estate tax to increase, respectively. "Petition" indicates she would write her Senator to increase the estate tax. "Min. wage" indicates support for increasing the minimum wage. "Trust" indicates trust in government and "Dem 2012" indicates the respondent plans to vote for the Democrat (Obama) in the 2012 Presidential election. "Covariates" and "scaled effects" are as specified in the notes to Table 4. The row "Control mean" reports the mean of the outcome variable in the control group. All regressions in this and subsequent tables include control variables as defined in Table $4 .{ }^{*} p<0.1,{ }^{* *} p<0.05,{ }^{* * *} p<0.01$

Table 6: Results from the follow-up survey one month later

\begin{tabular}{|c|c|c|c|c|c|c|c|c|}
\hline & \multicolumn{2}{|c|}{ Increase Estate Tax } & \multicolumn{2}{|c|}{ Govt scope } & \multicolumn{2}{|c|}{ Trust gov. } & \multicolumn{2}{|c|}{ Ineq. v. serious } \\
\hline & (1) & (2) & $(3)$ & (4) & (5) & (6) & (7) & (8) \\
\hline & First & Follow-up & First & Follow-up & First & Follow-up & First & Follow-up \\
\hline \multirow[t]{2}{*}{ Treated } & $0.337^{* * *}$ & $0.195^{* *}$ & 0.259 & $0.364^{*}$ & $-0.122^{* *}$ & -0.0691 & 0.00833 & 0.102 \\
\hline & {$[0.0953]$} & {$[0.0910]$} & {$[0.207]$} & {$[0.200]$} & {$[0.0611]$} & {$[0.0582]$} & {$[0.0809]$} & {$[0.0770]$} \\
\hline Control mean & 0.180 & 0.179 & 2.995 & 2.910 & 0.122 & 0.128 & 0.283 & 0.218 \\
\hline Obs. & 145 & 145 & 145 & 145 & 145 & 145 & 145 & 145 \\
\hline
\end{tabular}

Notes: All outcomes and terms are as defined in Tables 4 and 5. For each dependent variable, Column "First" is the result from the first survey, while Column "Follow-up" is the result from the follow-up survey one month after the initial survey. We use a more limited set of control variables given the small sample size. All regressions are run on the subsample of respondents who entirely completed the follow up survey. ${ }^{*} p<0.1,{ }^{* *} p<0.05,{ }^{* * *} p<0.01$ 
Table 7: Results from the estate tax survey

\begin{tabular}{|c|c|c|c|c|c|c|c|}
\hline & Ineq. v. ser. & Ineq. inc. & Deserving & Estate tax & Petition & Trust & Estate tax corr \\
\hline & (1) & $(2)$ & $(3)$ & (4) & $(5)$ & $(6)$ & $(7)$ \\
\hline Treated (Emotional) & $\begin{array}{c}0.0381 \\
{[0.0258]}\end{array}$ & $\begin{array}{r}-0.00239 \\
{[0.0243]}\end{array}$ & $\begin{array}{l}-0.0247 \\
{[0.0206]}\end{array}$ & $\begin{array}{l}0.289^{* * *} \\
{[0.0258]}\end{array}$ & $\begin{array}{c}0.0313 \\
{[0.0208]}\end{array}$ & $\begin{array}{l}-0.0164 \\
{[0.0205]}\end{array}$ & $\begin{array}{c}0.316^{* * *} \\
{[0.0263]}\end{array}$ \\
\hline Treated (Neutral) & $\begin{array}{c}0.0511^{* *} \\
{[0.0259]}\end{array}$ & $\begin{array}{c}-0.0501^{* *} \\
{[0.0244]}\end{array}$ & $\begin{array}{l}-0.0244 \\
{[0.0206]}\end{array}$ & $\begin{array}{l}0.109^{* * *} \\
{[0.0259]}\end{array}$ & $\begin{array}{c}0.0239 \\
{[0.0209]}\end{array}$ & $\begin{array}{c}-0.00558 \\
{[0.0205]}\end{array}$ & $\begin{array}{l}0.375^{* * *} \\
{[0.0264]}\end{array}$ \\
\hline Control mean & 0.307 & 0.771 & 0.174 & 0.210 & 0.132 & 0.153 & 0.120 \\
\hline Scaled Emot. Effect & 0.118 & 0.011 & 0.098 & 1.085 & 0.265 & 0.235 & 3.386 \\
\hline Scaled Neutral Effect & 0.159 & 0.223 & 0.097 & 0.408 & 0.202 & 0.080 & 4.014 \\
\hline P-Value & 0.612 & 0.049 & 0.991 & 0.000 & 0.722 & 0.598 & 0.026 \\
\hline Obs. & 1777 & 1777 & 1777 & 1777 & 1762 & 1756 & 1773 \\
\hline
\end{tabular}

Notes: The "emotional" treatment repeats the estate tax slide from the omnibus treatment, but eliminates the rest of the treatment. The "neutral" treatment is a version of the "emotional" treatment that attempts to remove any framing effects or emotional appeals to focus solely on the information. The outcomes in cols. (1) through (6) are as defined in Tables 4 and 5. ("Deserving" is the abbreviation for "the rich are deserving of their income"). "Estate tax corr." indicates that the respondent chose the correct multiple-choice outcome for a question asking what share of people who die are subject to the estate tax. $\mathrm{P}$-value is the $\mathrm{p}$-value of the test that the coefficients on the treated "emotional" and the treated "neutral" are the same. ${ }^{*} p<0.1,{ }^{* *} p<0.05,{ }^{* * *} p<0.01$

Table 8: Effect of negative trust prime on "first stage" variables

\begin{tabular}{|c|c|c|c|c|c|c|}
\hline & $\frac{\text { Trust }}{(1)}$ & $\frac{\text { Scope }}{(2)}$ & $\frac{\text { Efficient }}{(3)}$ & $\frac{\text { Ineq. v. ser. }}{(4)}$ & $\frac{\text { Ineq. inc. }}{(5)}$ & $\frac{\text { Pov. v. ser. }}{(6)}$ \\
\hline Treated & $\begin{array}{c}-0.0582^{* * *} \\
{[0.0203]}\end{array}$ & $\begin{array}{c}0.0236 \\
{[0.0688]}\end{array}$ & $\begin{array}{l}-0.0278 \\
{[0.0346]}\end{array}$ & $\begin{array}{l}0.0547^{*} \\
{[0.0311]}\end{array}$ & $\begin{array}{c}0.0119 \\
{[0.0289]}\end{array}$ & $\begin{array}{c}-0.00257 \\
{[0.0313]}\end{array}$ \\
\hline $\begin{array}{l}\text { Control mean } \\
\text { Scaled Trust Effect } \\
\text { Obs. }\end{array}$ & $\begin{array}{c}0.125 \\
1.730 \\
899\end{array}$ & $\begin{array}{c}3.031 \\
0.0170 \\
899\end{array}$ & $\begin{array}{c}1.423 \\
0.109 \\
898\end{array}$ & $\begin{array}{c}0.343 \\
0.182 \\
899\end{array}$ & $\begin{array}{c}0.755 \\
0.341 \\
899\end{array}$ & $\begin{array}{c}0.383 \\
0.00828 \\
899\end{array}$ \\
\hline
\end{tabular}

Notes: The negative trust prime treatment consists of several multiple-choice questions that made respondents reflect on aspects of government they dislike. For outcomes, "Efficient" is taken from a 1-3 scale of how much respondents think the government wastes money (we "flip" it so that it is increasing with perceived government efficiency). "Pov. v. ser." is an indicator variable for whether the respondent views poverty as a very serious problem. All other outcomes are as defined previously. ${ }^{*} p<0.1,{ }^{* *} p<0.05,{ }^{* * *} p<0.01$ 
Table 9: Effect of negative trust prime on outcome variables

\begin{tabular}{|c|c|c|c|c|c|c|c|c|}
\hline & $\frac{\$ 1 \mathrm{M} \text { tax }}{(1)}$ & $\frac{\text { Est. tax }}{(2)}$ & $\frac{\text { Petition }}{(3)}$ & $\frac{\text { Min. wage }}{(4)}$ & $\frac{\text { Aid poor }}{(5)}$ & $\frac{\text { Food st. }}{(6)}$ & $\frac{\text { Housing }}{(7)}$ & $\frac{\text { Priv. char }}{(8)}$ \\
\hline Treated & $\begin{array}{l}-0.0421 \\
{[0.0275]}\end{array}$ & $\begin{array}{r}-0.00168 \\
{[0.0266]} \\
\end{array}$ & $\begin{array}{c}-0.0602^{* *} \\
{[0.0236]}\end{array}$ & $\begin{array}{c}-0.00428 \\
{[0.0902]} \\
\end{array}$ & $\begin{array}{c}-0.139^{* *} \\
{[0.0616]}\end{array}$ & $\begin{array}{c}-0.153^{* *} \\
{[0.0673]}\end{array}$ & $\begin{array}{c}-0.163^{* * *} \\
{[0.0614]} \\
\end{array}$ & $\begin{array}{l}0.187^{* *} \\
{[0.0791]}\end{array}$ \\
\hline Control mean & 0.722 & 0.204 & 0.174 & 2.673 & 2.675 & 2.454 & 2.581 & 1.800 \\
\hline Scaled Trust Effect & 0.0949 & 0.00728 & 0.580 & 0.00531 & 0.128 & 0.119 & 0.133 & 0.169 \\
\hline Obs. & 899 & 895 & 899 & 899 & 899 & 899 & 899 & 850 \\
\hline
\end{tabular}

Notes: The negative trust prime treatment consists of several multiple-choice questions that made respondents reflect on aspects of government they dislike. Outcome variables are defined as follows. "Min. wage" is a 0-4 categorical variable increasing in support for the minimum wage ( 0 indicates most opposition and 4 indicates most support). "Food st." is a $0-4$ categorical variable increasing in support for food stamps. "Aid poor" is a 0-4 categorical variable increasing in support for programs that aid poor households. "Housing" is a 0-4 categorical variable increasing in support for funding public housing programs. "Priv. char." is an indicator of where (among a list of five policy approaches) the respondent puts "private charity" as a preferred method for addressing inequality (the variable increases with relative support for private charity). All other outcomes are as defined previously. ${ }^{*} p<0.1,{ }^{* *} p<0.05,{ }^{* * *} p<0.01$

Table 10: Effect of "emotional" treatment on outcome variables

\begin{tabular}{|c|c|c|c|c|c|c|c|c|}
\hline & $\frac{\text { Ineq. v. ser. }}{(1)}$ & $\frac{\text { Ineq. inc. }}{(2)}$ & $\frac{\text { Pov. v. ser. }}{(3)}$ & $\frac{\text { Min. wage }}{(4)}$ & $\frac{\text { Aid poor }}{(5)}$ & $\frac{\text { Food st. }}{(6)}$ & $\frac{\text { Housing }}{(7)}$ & $\frac{\text { Trust gov. }}{(8)}$ \\
\hline Treated & $\begin{array}{c}0.0783^{* * *} \\
{[0.0292]} \\
\end{array}$ & $\begin{array}{c}0.0410 \\
{[0.0258]}\end{array}$ & $\begin{array}{c}0.0885^{* * *} \\
{[0.0313]} \\
\end{array}$ & $\begin{array}{c}0.0469 \\
{[0.0989]} \\
\end{array}$ & $\begin{array}{c}0.117^{*} \\
{[0.0665]}\end{array}$ & $\begin{array}{l}0.177^{*} \\
{[0.101]} \\
\end{array}$ & $\begin{array}{c}0.0397 \\
{[0.0670]} \\
\end{array}$ & $\begin{array}{c}-0.00979 \\
{[0.0211]} \\
\end{array}$ \\
\hline Control mean & 0.337 & 0.775 & 0.296 & 2.546 & 2.559 & 1.832 & 2.539 & 0.124 \\
\hline Scaled Poverty Effect & 0.221 & 0.225 & 0.257 & 0.0449 & 0.0714 & 0.0866 & 0.0291 & 0.0931 \\
\hline Obs. & 1002 & 1001 & 799 & 799 & 799 & 799 & 799 & 1002 \\
\hline
\end{tabular}

Notes: The "emotional" treatment aimed at creating empathy between the respondent and families living in poverty. Respondents were told about poverty rates and filled out a minimum budget for a family like theirs living in the same city. Respondents were then shown how their minimum budget compared to the poverty line. All outcomes are as defined previously. "Min. wage", "Aid poor", "Food st.", "Housing" are all categorical 0-4 and increasing in support as in Table 9. The lower number of observations in columns 3-7 is due to the fact that these questions were not asked in one smaller wave (sample of 200 ). ${ }^{*} p<0.1,{ }^{* *} p<0.05,{ }^{* * *} p<0.01$ 
Table 11: Effect of policy treatment on outcome variables

\begin{tabular}{|c|c|c|c|c|c|c|c|c|}
\hline & $\frac{\text { Ineq. v. ser. }}{(1)}$ & $\frac{\text { Pov. v. ser. }}{(2)}$ & $\frac{\text { Min. wage }}{(3)}$ & $\frac{\text { Aid poor }}{(4)}$ & $\frac{\text { Food st. }}{(5)}$ & $\frac{\text { Housing }}{(6)}$ & $\frac{\text { Priv. char. }}{(7)}$ & $\frac{\text { Trust gov. }}{(8)}$ \\
\hline Policy Treatment & $\begin{array}{c}0.0405 \\
{[0.0279]}\end{array}$ & $\begin{array}{c}-0.00637 \\
{[0.0272]}\end{array}$ & $\begin{array}{l}0.323^{* * *} \\
{[0.0949]}\end{array}$ & $\begin{array}{l}0.133^{* *} \\
{[0.0638]}\end{array}$ & $\begin{array}{l}0.313^{* * *} \\
{[0.0970]}\end{array}$ & $\begin{array}{l}0.176^{* * *} \\
{[0.0636]}\end{array}$ & $\begin{array}{l}-0.137^{*} \\
{[0.0709]}\end{array}$ & $\begin{array}{l}-0.0325 \\
{[0.0207]}\end{array}$ \\
\hline $\begin{array}{l}\text { Control mean } \\
\text { Scaled Policy Effect } \\
\text { Obs. }\end{array}$ & $\begin{array}{l}0.343 \\
0.108 \\
1111\end{array}$ & $\begin{array}{c}0.326 \\
0.0196 \\
1111\end{array}$ & $\begin{array}{c}2.546 \\
0.310 \\
806\end{array}$ & $\begin{array}{c}2.559 \\
0.0811 \\
806\end{array}$ & $\begin{array}{c}1.832 \\
0.153 \\
806\end{array}$ & $\begin{array}{c}2.539 \\
0.129 \\
806\end{array}$ & $\begin{array}{c}2.025 \\
0.0740 \\
1068\end{array}$ & $\begin{array}{l}0.149 \\
0.654 \\
1111\end{array}$ \\
\hline
\end{tabular}

Notes: The policy treatment aimed at creating empathy between the respondent and families living on a minimum wage. Respondents filled out a minimum budget for a family like theirs living in the same city. Respondents were then shown how their minimum budget compared to the minimum wage and how food stamps add $\$ 150$ per person/month to the budget of such a family. All outcomes are as defined previously. "Min. wage", "Aid poor", "Food st.", "Housing" are all categorical 0-4 and increasing in support as in Table 9. The lower number of observations in columns 3-7 is due to the fact that these questions were not asked in one smaller wave (sample of 300). ${ }^{*} p<0.1,{ }^{* *} p<0.05,{ }^{* * *} p<0.01$ 


\section{Web Appendix of}

\section{How Elastic are Preferences for Redistribution? Evidence from Randomized Survey Experiments}

\section{By Ilyana Kuziemko, Michael I. Norton, Emmanuel Saez, and Stefanie Stantcheva}

\section{A Detailed Description of the Experiment}

\section{A.1 Omnibus Treatment Description}

This Section describes in detail the omnibus experiment. The omnibus treatment experiment was carried out in 4 separate rounds from January 2011 to August 2012. The structure of the experiment was as follows:

(1) Background socio-economic questions including age, gender, race, marital status, children, state of residence, education, household income, work status, whether the respondent considers himself conservative or liberal on economic policy, voting choice in 2008 presidential election.

(2) Randomized treatment showing information on inequality, the estate tax, and tax policy shown solely to the treatment group. Those treatments are illustrated through screenshots in appendix Figures 1, 2, 3, and 4.

(3) Set of questions on inequality, taxes and transfers, policy views and 2012 voting plans. Those questions are listed in detail after the screenshots.

Surveys were openly posted on mTurk and their description stated that they would pay $\$ 1.50$ for approximately 15 minutes of survey time, i.e., a $\$ 6$ hourly wage. People were free to drop out any time or take up to one hour to answer all questions.

Round 3 was conducted with CT Marketing Group instead of mTurk at a cost of $\$ 5$ per respondent. The survey software remained exactly the same.

The link to this survey is: https://hbs . qualtrics .com/SE/?SID=SV_77fSvTy12ZSBihn

\section{List of all Outcome Questions}

Note: Sentences in italic were not seen by the respondents. Bold fonts are just labels for each section. Sentences in normal font are exactly as they appeared in the survey. Text in bracket represents the answer choices given to respondents. Text in curly brackets are explanatory notes for the readers of this paper (not presented to respondents).

Tax rate questions:

1. Choose the tax rate on the top 1\%, next 9\%, next $40 \%$ and bottom $50 \%$ (see screenshot). [Slider with continuous percentage choices $0 \%-100 \%$ for each of the four income groups]

2. Do you think top income tax rates were higher in the 1950s and 1960s than they are today? [Yes, higher in the 1950s and 1960s/No, lower in the 1950s and 1960s] 
3. As you may know, there have been proposals recently to decrease the federal deficit by raising income taxes on millionaires. Do you think income taxes on millionaires should be increased, stay the same or decreased? [Increased/Stay the same/Decreased]

4. The Federal Estate tax (also known as the Death Tax) is a tax imposed on the transfer of wealth from a deceased person to his or her heirs. Do you think the Federal Estate tax should be decreased, left as is or increased? [Decreased/Left as is/Increased]

First stage questions on knowledge and perceptions of inequality:

5. Do you think annual economic growth was faster in the period 1980-2010 than in the period 1933-1980? [Faster in 1980-2011/The same in both periods/Faster in 1933-1980]

6. Do you think inequality is a serious problem in America? [Not a problem at all/A small problem/A problem/A serious problem/A very serious problem]

7. Do you think income inequality in the US has increased or decreased in recent decades? [Decreased/Stayed the same/Increased]

8. Are you satisfied with your current income? [Very satisfied/Somewhat satisfied/Not too satisfied/Not at all satisfied]

9. Do you think that the very high earners in our society deserve their high incomes? [Most of the time/Sometimes/Rarely]

10. Which statement do you agree with most? [A: "One's income and position in society is mostly the result of one's individual effort" / B: "One's income and position in society is to a large extent the outcome of elements outside of one's control (for example, including but not limited to family background, luck, health issues, etc..)"?]

\section{Political Outcomes:}

11. Which party do you plan to support in the 2012 presidential elections? [Democratic/Republican/Other/None] \{note: the surveys were carried out before the 2012 elections\}

12. How much of the time do you think you can trust government in Washington to do what is right? [Just about always/Most of the time/ Only some of the time/ Never]

13. Next, think more broadly about the purpose of government. Where would you rate yourself on a scale of 1 to 5 , where 1 means you think the government should do only those things necessary to provide the most basic government functions, and 5 means you think the government should take active steps in every area it can to try and improve the lives of its citizens? [1/2/3/4/5]

14. What do you think the most important goal of the federal income tax should be? [Raise money for infrastructure projects such as roads and bridges/ Raise money for universal social services such as Social Security and Medicare/ Raise money from the wealthiest citizens to support programs that aid low-income citizens, such as Medicaid and Food Stamps)]

\section{Poverty Reduction Policies Outcomes:}

15. The minimum wage is currently $\$ 7.25$ per hour. Do you think it should be decreased, stay the same or increased? [Decreased/Stay the same/Increased]

16. Do you support or oppose the Earned Income Tax Credit (EITC) program? [Support/Indifferent/Oppose]

17. Do you support or oppose the Food Stamps program? [Support/Indifferent/Oppose] 
18. In the next month, do you plan to donate any money to an organization that supports those in need? [Yes/No]

19. In the past month, have you donated any money to an organization that supports those in need? [Yes/No]

20. In the next month, do you plan to donate some of your time to an organization that supports those in need? [Yes/No]

21. In the past month, have you donated some of your time to an organization that supports those in need? [Yes/No]

\section{Real Outcome: Petition for Estate Tax}

22. Writing to the Senators of your state gives you an opportunity to influence taxation policy. Few citizens email their elected officials, therefore Senators and their staff take such emails from their constituents very seriously. If you would like to write to your Senator, go to the official US Senate list and click on your Senator's contact webpage. Two sample letters are provided below, one asking for higher estate taxes on the rich, one asking not to increase estate taxes on the rich. Feel free to cut-and-paste and edit the text before sending it to your Senator. Most Senators' websites ask for your name and address to avoid spam. We are not able to record what you write on the external (Senator's) website, so your letter and private information are kept fully confidential.

For the purpose of our survey, we would just like to know from you: I sent or will send an email to my Senator asking for higher estate taxes on the rich/ I sent or will send an email to my Senator asking to not increase estate taxes on the rich/ I do not want to email my Senator

Sample letter for higher estate taxes on the rich: Dear Senator, In the coming months as you debate the federal budget, one of the priorities for Congress should be raising estate taxes on the wealthiest Americans so that they pay their fair share to fund government programs and help solve our federal budget deficit problem.

Sample letter for not increasing estate taxes on the rich: Dear Senator, In the coming months as you debate the federal budget, one of the priorities for Congress should be keeping estate taxes on the wealthiest Americans low. The government should not punish people who are financially successful or well-off.

[I sent or will send an email to my Senator asking for higher estate taxes on the rich/I sent or will send an email to my Senator asking to not increase estate taxes on the rich/I do not want to email my Senator]

\section{A.2 Estate Tax Experiment Description}

The follow up estate tax experiment was conducted in March 2014 on a sample of 1800 respondents. Respondents were randomized into one of two treatment groups, or into the control group. The first treatment group saw the same screen as in the omnibus treatment (only the part regarding the estate tax), as in appendix Figure 4. The second group saw a plain explanation for the estate tax, as in appendix Figure 6.

The link to this experiment is: https://hbs .qualtrics.com/SE/?SID=SV_0v0ecp2MDPBpInb

\section{List of all Outcome Questions}


Note: Sentences in italic were not seen by the respondents. Bold fonts are just labels for each section. Sentences in normal font are exactly as they appeared in the survey.

1. Choose the tax rate on the top 1\%, next 9\%, next 40\% and bottom 50\% (see screenshot). [Slider with continuous percentage choices $0 \%-100 \%$ for each of the four income groups]

2. Do you think income inequality in the United States has increased or decreased since 1980? [Decreased/Stayed the same/Increased]

3. Do you think inequality is a serious problem in America? [Not a problem at all/A small problem/A problem/A serious problem/A very serious problem]

4. The Federal Estate Tax is a tax imposed on the transfer of wealth from a deceased person to his or her heirs. What percentage of people who die have to pay the Federal Estate tax? If you don't know, just give your best guess. [Less than 1\%/1\%/10\%/20\%/40\%/60\%/100\%]

5. Do you think poverty is a serious problem in America? [Not a problem at all/A small problem/A problem/A serious problem/A very serious problem]

6. Do you think that the very high earners in our society deserve their high incomes? [Most of the time/Sometimes/Rarely]

7. Do you think the federal estate tax should be decreased, left as is or increased? (Recall that the federal estate tax is a tax imposed on the transfer of wealth from a deceased person to his or her heirs.) [Decreased/Left as is/Increased]

8. As you may know, there have been proposals recently to decrease the federal deficit by raising income taxes on millionaires. Do you think income taxes on millionaires should be increased, stay the same or decreased?[Increased/Stay the same/Decreased]

9. Which of the tools below do you consider the best to address inequality in the United States? Please drag and drop the items to the box on the right and rank them in your preferred order. Your preferred method for addressing inequality should be at the top, your least preferred one at the bottom. [Education Policies, Private Charity, Progressive Taxes, Government Transfers (e.g., food stamps, Medicaid,..), Government regulation (e.g., min wage, caps on top compensation,...)]

10. Should the federal government increase or decrease spending on aid to the poor? [Significantly increase/Slightly increase/Keep at current level/Slightly decrease/Significantly decrease]

11. The federal minimum wage is currently $\$ 7.25$ per hour. Do you think it should be decreased, stay the same or increased? [Significantly increased/Slightly increased/Stay the same/Slightly decreased/Significantly decreased]

12. Should the federal government increase or decrease its spending on public housing for low income families? [Significantly increase /Slightly increase/Keep at current level/Slightly decrease/Significantly decrease]

13. Should the federal government increase or decrease its spending on food stamps? (Food stamps provide financial assistance for food purchasing to families and individuals with low or no income.) [Significantly increase/Slightly increase/Keep at current level/Slightly decrease/Significantly decrease]

14. Petition for Estate Tax: same as in A.1

15. Which party do you plan to support in the 2014 congressional elections? [Democratic/Republican/Other/None]

16. How much of the time do you think you can trust government in Washington to do what is right? [Just about always/Most of the time/Only some of the time/Hardly ever] 
17. Next, think more broadly about the purpose of government. Where would you rate yourself on a scale of 1 to 5, where 1 means you think the government should do only those things necessary to provide the most basic government functions, and 5 means you think the government should take active steps in every area it can to try and improve the lives of its citizens? $[1 / 2 / 3 / 4 / 5]$

18. Do you think that people in the government waste a lot of money we pay in taxes, waste some of it, or don't waste very much of it?" [Waste a lot of money we pay in taxes/Waste some of the money we pay in taxes/Don't waste much of the money we pay in taxes]

19. How do you feel about the following statement: "Currently, the federal government is very effective in limiting fraud, waste and abuse in the programs it administers"? [Strongly agree/Agree/Disagree/Strongly disagree]

20. How do you feel about the following statement: "Politicians in Washington work to enrich themselves and their largest campaign contributors, instead of working for the benefit of the majority of citizens"? [Strongly agree/Agree/Disagree/Strongly disagree]

\section{A.3 Emotional Poverty Experiment}

The emotional poverty treatment was conducted in March 2014 on a sample of 1200 respondents. Respondents were first as usual asked for their demographic information. Depending on their answers to the questions about their marital status and whether they have children living with them, they were redirected to a specific, customized branch. They were then randomized into treatment and control group. The treatment group saw information about poverty that was adapted to their family situation, without knowing that the information was actually customized. Each respondent estimated the basic expenses that a family of the configuration of his own family (living where the respondent lives) would have to incur for rent, utilities, transportation to work, food, and, depending on the family situation, expenses for children. Appendix Figure 9 shows the screenshot where respondents were asked to estimate the minimal budget of a family similar to theirs. Between this page and the next, the program computed the total expenses estimated. If those were above the actual poverty threshold for the family, the next page told respondents that given their estimates, the family would fall short by such and such amount. If the total was below the poverty threshold, the next page told respondents that given their estimates, the family would only be left with such and such amount for all other expenses.

The link to the survey is https://hbs.qualtrics.com/SE/?SID=SV_1B8MczKSMIvWaqx

The outcome questions were the same as in section A.2, except that the question about how many people pay the estate tax was not asked. Instead the following three questions were added:

1. What percentage of Americans live in poverty? If you don't know, just give your best guess. (Poverty is officially defined as having monthly resources below $\$ 970$ for a single person, $\$ 1310$ for a two person family, $\$ 1650$ for a three person family, etc...) [Less than $5 \%$ $/ 9 \% / 16 \% / 24 \%]$.

2. What percentage of children under age 18 live in poverty in the US, approximately? If you don't know, just give your best guess. [10\%/20\% / 30\% / 40\%]. 
3. How many workers in the US earn the minimum wage? If you don't know, just give your best guess. [2 million / 6 million / 10 million].

\section{A.4 Policy Experiment}

The policy experiment was conducted in March 2014 on a sample of 1300 respondents. Respondents were randomized into a control group or a treatment group. The treatment group was again redirected to a customized branch, depending on their answers to the questions about their marital status and whether they had children living with them. In the treatment screens, they were asked about and shown information about a family whose configuration was similar to theirs. First, respondents were asked to estimate the minimum expenses necessary for a family earning the minimum wage, for rent, utilities, transportation to work, food, and, if applicable, children expenses. That screen is shown in appendix Figure 10. Between this page and the next, the program computed the total expenses implied and informed the respondents either of the shortfall that the family living on a single minimum wage would have to face, or the surplus that would be left over, if they had to incur the expenses as estimated by the respondent. That second screen also showed information about the food stamps program, informing respondents that: "The Food Stamps program helps many low income families, such as those earning only one minimum wage. It provides $\$ 150 /$ month per person to help with food expenses."

The link to the experiment is https://hbs.qualtrics.com/SE/?SID=SV_1B8MczKSMIvWaqx.

The outcome questions were exactly the same as in section A.3.

\section{A.5 Trust Experiment}

The trust treatment was conducted in March 2014 on a sample of 1000 respondents. The treatment showed people information about how the United States is ranked in terms of corruption among a list of countries of similar income and development levels (the United States is ranked in the worst group of countries given income and development levels), as shown in appendix Figure 8.

The link to this survey is in: https://hbs . qualtrics . com/SE/?SID=SV_bgEuJfl1Y3UreKh

Respondents in the treatment group were asked questions designed to elicit negative reactions regarding the government. The full list of questions were:

1. What is your view of the "Wall Street bailout", the legislation signed into law by President Bush in 2008 whereby the federal government lent $\$ 700$ billion to banks and other financial institutions that faced bankruptcy? [Strongly support this legislation/Support this legislation/Oppose this legislation/Strongly oppose this legislation]

2. Because of a recent Supreme Court decision, for the first time in decades there are now no limits on the amount of money that corporations and other special interests can give to political campaigns for President or Congress. Do you agree with the following statement: "Corporations and other specials interests have far too much influence on politicians in Washington"? [Strongly agree/Agree/Disagree/Strongly disagree]

3. How do you feel about the following statement: "Currently, the federal government is very effective in limiting fraud, waste and abuse in the programs it administers"? [Strongly agree/Agree/Disagree/Strongly disagree] 
4. How much confidence do you have in the federal government's administering of economic and military aid to foreign countries (which totals over $\$ 50$ billion annually)? [A great deal of confidence/Some confidence/Little confidence/No confidence]

5. How do you feel about the following statement: "Politicians in Washington work to enrich themselves and their largest campaign contributors, instead of working for the benefit of the majority of citizens"? [Strongly agree/Agree/Disagree/Strongly disagree]

The outcome questions were the same as in section A.2, except that we did not ask any of the knowledge questions about poverty rates, child poverty rates, minimum wage earners, or how many people pay the estate tax.

\section{A.6 List of all constructed variables}

Below we provide a full definition of all variables used in the tables. In brackets, we provide the coding of the variable.

- "Ineq vs." (or "Ineq. v. serious") is a binary variable equal to 1 if the respondent replies that "inequality is a very serious problem." [0/1]

- "Ineq. inc." (or "Ineq. increased") is a binary variable equal to 1 if the respondent replies that inequality has increased since 1980. [0/1]

- "Deserving" (or "Rich deserving") is a binary variable equal to 1 if the respondent believes that the rich are deserving of their income "most of the time." [0/1]

- "Top tax" (or "Top tax rate") is the chosen average tax rate on the richest one percent. [0 to 100]

- "Mill. tax" (or "Increase Mill. Tax") is an indicator variable for whether the respondent wants to increase the income tax on millionaires. [0/1]

- "Estate tax" (or "Increase Estate Tax") is an indicator variable for whether the respondent wants to increase the estate tax. $[0 / 1]$

- "Petition" is an indicator variable for whether the respondent wants to send a petition to her State Senator to increase the estate tax. [0/1]

- "Min. wage" in the omnibus treatment indicates support for increasing the minimum wage. $[0 / 1]$

- "Min wage" in the follow up surveys indicates the strength of the support for increasing the minimum wage $[0 / 1 / 2 / 3 / 4$, increasing in support].

- "Aid" indicates support for expanding aid to the poor. [0/1/2/3/4, increasing in support].

- "Housing" indicates support for expanding funding for public housing. [0/1/2/3/4, increasing in support]. 
- "Food stamps" in the omnibus indicates support for expanding the food stamps program. $[0 / 1]$

- "Food stamps" in the followup surveys indicates the strength of the support for expanding the food stamps program $[0 / 1 / 2 / 3 / 4$, increasing in support].

- "EITC" indicators support for expanding funding for the EITC. [0/1]

- "Trust" or ("Trust govt") is an indicator variable for whether the respondent believes the government can be trusted. [0/1]

- "Scope" (or "Govt scope") is a categorical variable indicating how active the government should be in redistributing income. $[1 / 2 / 3 / 4 / 5,5$ being the broadest scope of government].

- "Dem 2012" indicates that the respondent plans to vote for the Democrat (Obama) in the 2012 Presidential election. [0/1]

- "Dem 2014" indicates that the respondent plans to vote for the Democrat in the 2014 Congressional election. [0/1]

- "Taxes redistr." indicates that the respondent thinks that the role of income taxes is to redistribute income (as opposed to just financing infrastructure). [0/1]

- "Growth" indicates that the respondent's reply to the question of whether growth was higher in 1933-1980 than in 1980-200 was correct. [0/1]

- "Tax 1950" indicates that the resppndent's reply to the question whether top income taxes were higher in the 1950 s than today was correct. [0/1]

- "Satisfied" indicates whether the respondent is satisfied with his current income. [0/1]

- "Money charity" is a dummy variable for whether the respondent plans to give money to charity in the next month. [0/1]

- "Money given" indicates whether he has already given money in the past month. [0/1]

- "Time charity" is a dummy variable for whether the respondent plans to give time to charity in the next month. [0/1]

- "Time given" indicates whether he has already given time in the past month. [0/1]

- "Income mostly result of effort" is a binary variable indicating that the respondent believes that one's income is mostly the result of one's own effort. [0/1]

- "Tax on next 9\%", "Tax on next $40 \%$ " and "Tax on Bottom 50\%" are the respondent's chosen tax rates for, respectively, people in the 90th to 99th percentile, in the 50th to 90th percentile and in the Bottom half of the income distribution. [0 to 100]

- "Diff tax top 1 and Bottom 50" is the tax differential between the preferred tax on the top $1 \%$ and that on the Bottom $50 \%$. 
- "Charities" refers to the ranking (from 1 to 5 , with 1 being the highest ranking) that respondents attribute to private charities as a means to redistribute income. $[1 / 2 / 3 / 4 / 5]$

- "Educ. pol" refers to the ranking (from 1 to 5, with 1 being the highest ranking) that respondents attribute to education policies as a means to redistribute income. $[1 / 2 / 3 / 4 / 5]$

- "No waste" takes values from 1 to 3 , with 1 representing that the government is wasting a lot of tax revenue and 3 indicating that the government is not wasting much tax revenue at all. $[1 / 2 / 3]$

\section{B Methodological issues related to online survey experiments}

In this section, we share what we have learned through our experience with these mTurk survey experiments to highlight both the advantages and disadvantages of using online surveys for research as well as provide advice for future researchers.

The most obvious advantage is the ease and speed of gathering relatively large samples. At a per-survey price of $\$ 1.50$ it typically took at most five or six days to gather a sample of 1,000 U.S. residents, and samples of 300-400 could usually be gathered within 24 hours. An important piece of advice for future researchers studying American domestic policy questions is to ask mTurk to limit the sample to U.S. residents (Amazon documents this information for tax purposes). In pilot surveys we conducted before becoming aware of this problem, over forty percent of our respondents turned out to have non-U.S. IP addresses (likely an ever greater share were foreign residents since respondents can connect through remote servers and appear to be in the US). Launching surveys at night (during the workday in Asia) exacerbates this problem.

\section{B.1 How representative is the mTurk sample?}

As noted earlier, respondents to our surveys are not representative of the U.S. population. However, this lack of representativeness does not appear substantially worse than in other surveys. For example, the mTurk sample is about 13 years younger and 13 percentage points more likely to have a college degree than the representative sample of U.S. adults in our national CBS sample (see Table 1). But that same CBS poll we use as a basis for comparison is itself weighted. The raw CBS sample is about nine years older than the weighted sample and, like our mTurk sample, about 13 percentage points more likely to have a college degree. It under-represents Hispanics to the same extent as our sample and is even worse than our sample in terms of the under-representation of men. As such, while the mTurk sample is not representative, neither are other standard polls (though some of the biases, such as age, are in opposite directions from standard polls).

As noted in the text, the American Life Panel is more representative than the mTurk sample. However, this sample is much smaller and roughly 30 times more expensive than mTurk. 


\section{B.2 How serious is attrition in the mTurk sample?}

As noted earlier, for the omnibus treatment, we have an overall attrition rate (the share of respondents who start but do not finish the survey) of 22 percent: a 21 percent rate for the CT Marketing Group survey and a 22 percent rate for the mTurk surveys. In fact, when we compare surveys 4 and 5 -which were in the field at the same time, with the former on mTurk and the latter on CT Marketing Group - attrition is actually lower on mTurk. Even Gallup has an attrition rate of nine percent on its 15 -minute Daily Poll. ${ }^{45}$ Given that our survey requires people to read through informational treatments, we suspect that a pure opinion survey conducted on mTurk would have a lower attrition rate.

The omnibus survey has differential attrition between treatment and control, probably because of the relatively long length of the treatment (respondents had to scroll through 6 treatment pages in the omnibus survey). Importantly, the follow-up surveys do not have such differential attrition because the treatment was much shorter (2 pages at most) so that there was no noticeable length difference between the treatment and control group.

A related point is that researchers using this methodology should ask background questions first. In settings with little to no attrition, background questions can ideally be asked at the very end to avoid priming, but given the importance of assessing non-random attrition, it may be preferable for online survey experiments to ask demographic and background questions at the outset.

\section{B.3 How many unique observations can one collect on mTurk?}

Although the exact number of workers registered on mTurk is not publicly reported, the pool is thought to be quite large, approximately 500,000.

However, the pool available for any given survey experiment is more limited. First, workers select into tasks voluntarily, choosing among types of tasks. As a result, the pool of workers interested in survey experiments is more limited. Indeed survey experiments are typically longer than a standard task on mTurk and might require more attention. Second, we filter workers based on past ratings: this is to avoid careless workers who consistently do not complete tasks properly and have been rated negatively by previous amazon mTurk requesters (i.e., employers on mTurk). Third, the pool of registered workers is not online all the time. Many workers could be working for a few weeks, then switch to another occupation, and potentially come back later or only work during some times of the year, month, or week. Finally, there is competition between tasks. Many tasks are posted simultaneously on the platform and workers have to search for each individual task. Large sample survey experiments sometimes fall lower in the list and are less visible to workers (although, one way to make it more visible and which we employ, is to stop and relaunch the survey several times so that it moves back up to the top of the list of tasks).

We always exclude workers who have already taken one of our survey experiments in the past to avoid any spillovers from previous treatments. Hence, we need a fresh sample every time. Accordingly, we noticed that when we launch a survey experiment several weeks after a

\footnotetext{
${ }^{45}$ Email correspondence when Jeffrey Jones at Gallup, January 16, 2013. The nine-percent figure refers to all Daily Polls from 2012.
} 
previous one, we easily get a large sample very quickly. However, when we repeatedly launch experiments one after the other, the rate at which we get workers slows down.

To mitigate the constraint of being unable to reach a sufficiently large sample of workers, researchers can do all of the following: a) leave sufficient times between survey dates, b) pay sufficiently high wages to make the tasks competitive relative to others, c) keep survey time short, d) choose more generic titles for the task, such as "Opinion Survey" rather than "Academic Research Survey in Economics." However, researchers should be warned that even after taking these steps, survey samples are not unlimited in mTurk and if "fresh" respondents are needed for each survey date a large share of respondents clicking on the task will be screened out (or will need to be dropped ex-post based on repeated mTurk worker IDs). 
Appendix Figure 1: Inequality Component: "Where are you in the income distribution?"

Please enter your annual household income* in the box below:

$\$ 25000$

$39 \%$ of US households earn less than your household

\begin{abstract}
We now encourage you to move the blue slider above (by clicking on the line) to explore the US income distribution on your own and to answer the questions below.
\end{abstract}

$79 \%$ of households earn less than $\$ 73,000$.

Notes: This interactive slider allows people to explore the income distribution in the US and to determine their position in it. Available online at

https://hbs .qualtrics. com/SE/?SID=SV_77fSvTy12ZSBihn 
Appendix Figure 2: Inequality component: "Where would you have been in the income distribution?"

\footnotetext{
Income Inequality has increased dramatically in the United States since 1980.

Incomes of poorer and middle-income families have grown very little while top incomes have grown a lot.
}

\section{How would YOU be doing if inequality had not increased?}

The slider below shows how much each group would make if incomes had grown by the same percentage since 1980 for all groups: the poor, the middle class, and the rich. Use the slider to answer the questions below.

\section{A household making $\$ 25,800$ today would instead be making \\ $\$ 35,200$ if inequality had not changed since 1980 . \\ In other words, if growth had been evenly shared, this household would have earned $37 \%$ more.}

Notes: This interactive slider shows the "counterfactual" household income had income growth been shared equally since 1980. Available online at https://hbs.qualtrics.com/SE/?SID=SV_77fSvTy12ZSBihn 
Appendix Figure 3: Taxes component: Correlation between growth and top tax rates over time
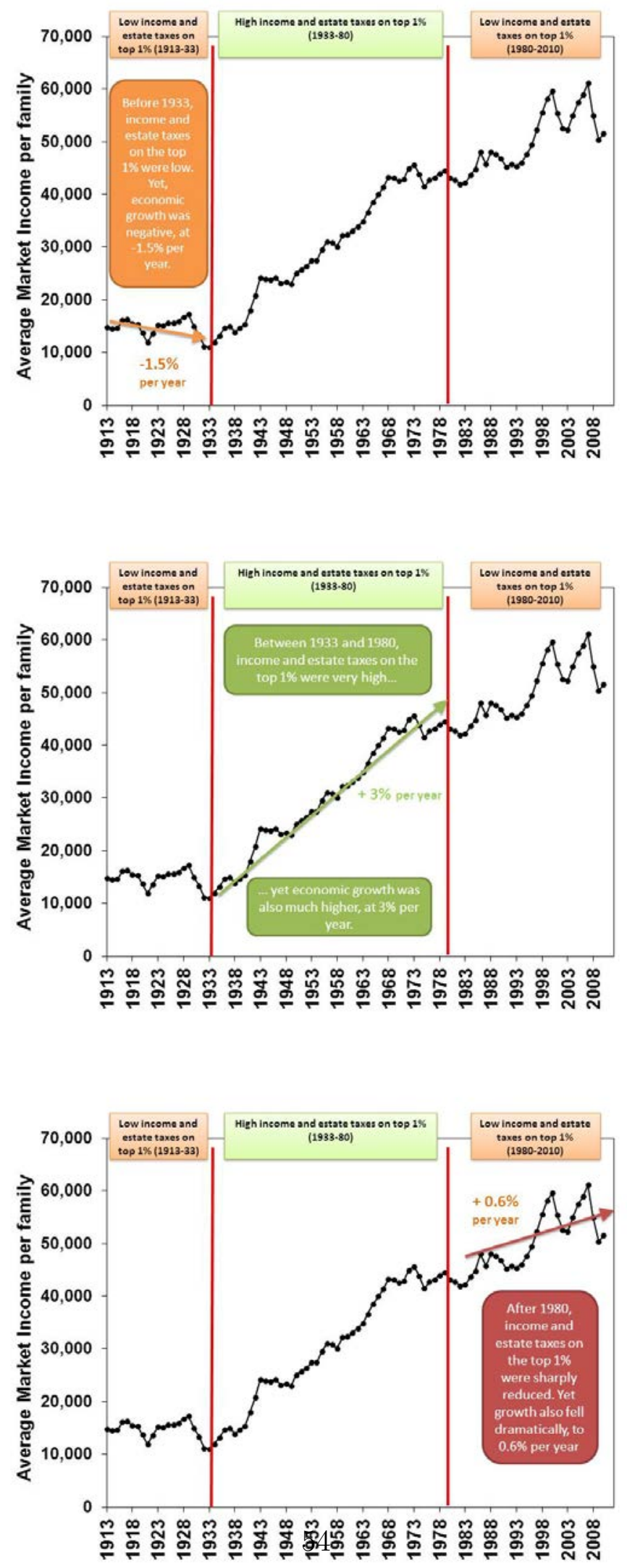
Appendix Figure 4: Showing information about the estate tax

Besides the income tax, the government can also level the playing field with the federal estate tax.

The Federal Estate Tax (also known as the Death Tax) applies when a deceased person leaves more than $\$ 5$ million in wealth to his or her heirs. Wealth left to a spouse or charitable organizations is exempt from estate tax.

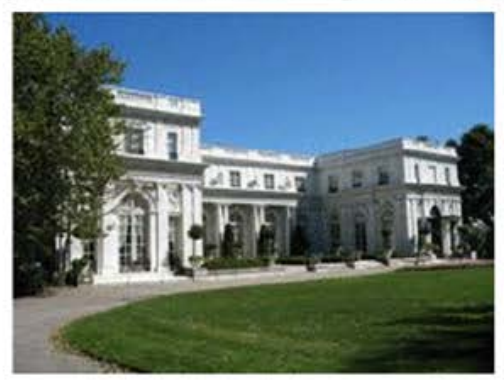

Only 1 person out of 1000 is wealthy enough to face the estate tax.

Average Americans do not have anything close to $\$ 5$ million in wealth, so the estate tax does not affect them and they can pass on their property to their children tax-free.

Eliminating the estate tax would allow the very richest families to pass down all of their wealth to their children tax-free. Hence, children of rich people would also start off very rich themselves.

Increasing the estate tax is a way to level the playing field between the children of wealthy parents and children of middle-class parents.

Notes: Available online at

https://hbs.qualtrics.com/SE/?SID=SV_77fSvTy12ZSBihn 
Appendix Figure 5: Preferred tax rates outcome

Now we would like to ask you about the income tax rates that you think different people SHOULD pay.

The income tax rate is the percentage of your income that you pay in federal income tax. For example, if you earn $\$ 30,000$ and you pay $\$ 3,000$ in income taxes, your income tax rate is $10 \%$.

Please use the sliders below to tell us how much you think each of the following groups should pay as a percentage of their total income.

The Top $1 \%$ (richest)

The next $9 \%$ ( $1 \%$ of Households earn more than them, $90 \%$ earn less)

The next $40 \%$ ( $10 \%$ earn more than them, $50 \%$ earn less)

$5 \%$

The Bottom $50 \%$ (poorest)

Notes: Available online at https://hbs.qualtrics.com/SE/?SID=SV_77fSvTy12ZSBihn 
Appendix Figure 6: Neutral information about the estate tax

The Federal Estate Tax applies when a deceased person leaves more than $\mathbf{\$ 5}$ million in wealth to his or her heirs. Wealth left to a spouse or charitable organizations is exempt from estate tax.

\section{Only 1 person out of 1000 is wealthy enough to face the estate tax.}

Average Americans have far less than $\$ 5$ million in wealth when they die, so the estate tax does not affect them and they can pass on their property to their children tax-free.

Notes: Available online at

https://hbs.qualtrics.com/SE/?SID=SV_0v0ecp2MDPBpInb 
Appendix Figure 7: A word cloud based on open-ended responses to the question "How much of the time can you trust the government in Washington to do what is right?"

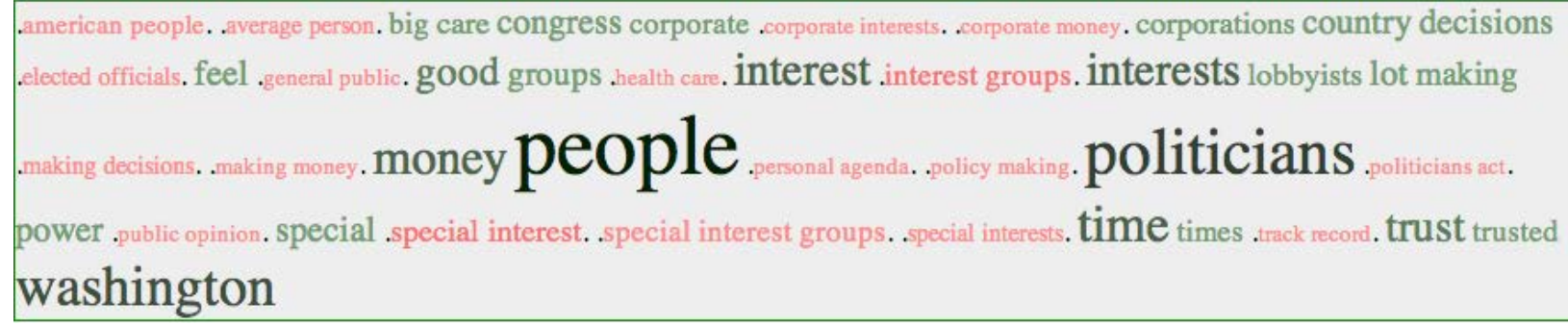

Notes: Based on the pilot group survey on mTurk described in Section 4.2. 
Appendix Figure 8: Negative information about corruption in the U.S.

Each year, the non-partisan organization Transparency International rates countries based on the amount of government corruption. When the US is compared to countries with similar levels of income and development how do you think it ranks?

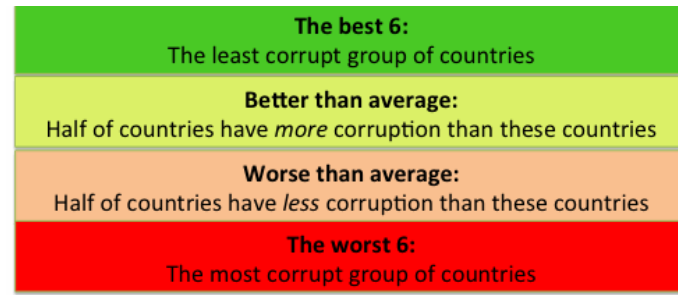

\begin{tabular}{|c|c|c|c|}
\hline The best 6 & Better than average & Worse than average & The worst 6 \\
\hline 0 & 0 & 0 & 0 \\
\hline
\end{tabular}

These are the actual results from the report:

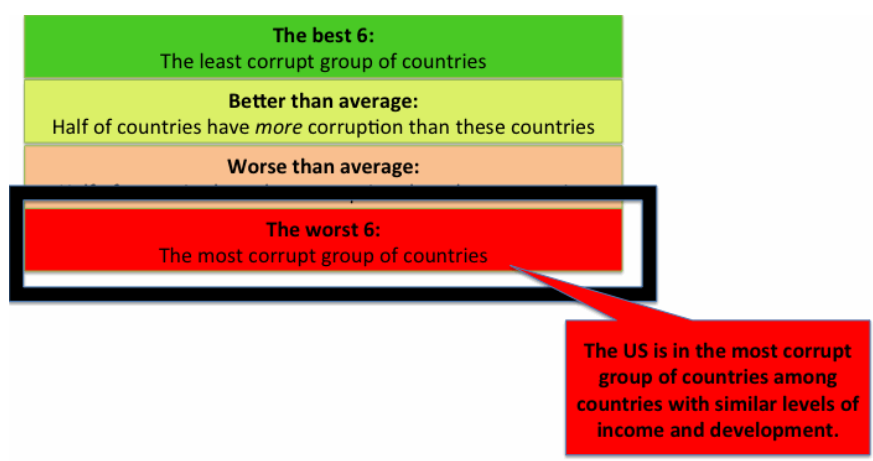

Notes: Available online at

https://hbs.qualtrics.com/SE/?SID=SV_bgEuJfl1Y3UreKh 
Appendix Figure 9: Customized information about poverty

The picture of poverty in a rich country like the United States is striking.

$16 \%$ of Americans live in poverty.

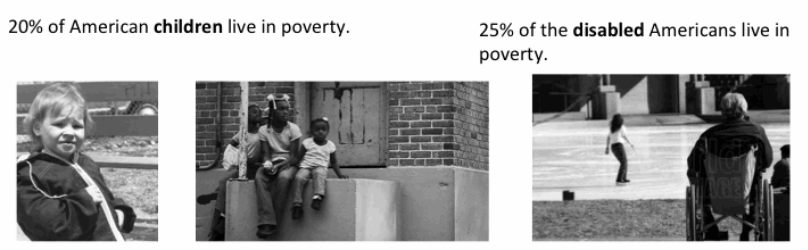

Think about a family of four with two parents working full time at low pay and two kids.

What would be the minimal monthly expenses that such a family would have to make to afford living in your city?

Please enter numbers only, with no "\$" sign and no commas, e.g., 1000.

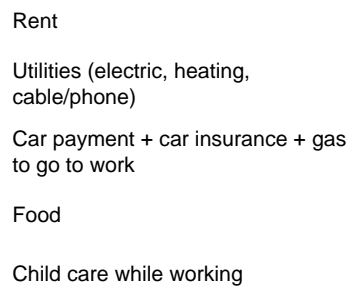

Child care while working

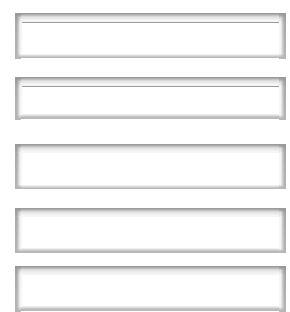

Notes: Available online at https : //hbs . qualtrics . com/SE/?SID=SV_1B8MczKSMIvWaqx 
Appendix Figure 10: Customized information about policies
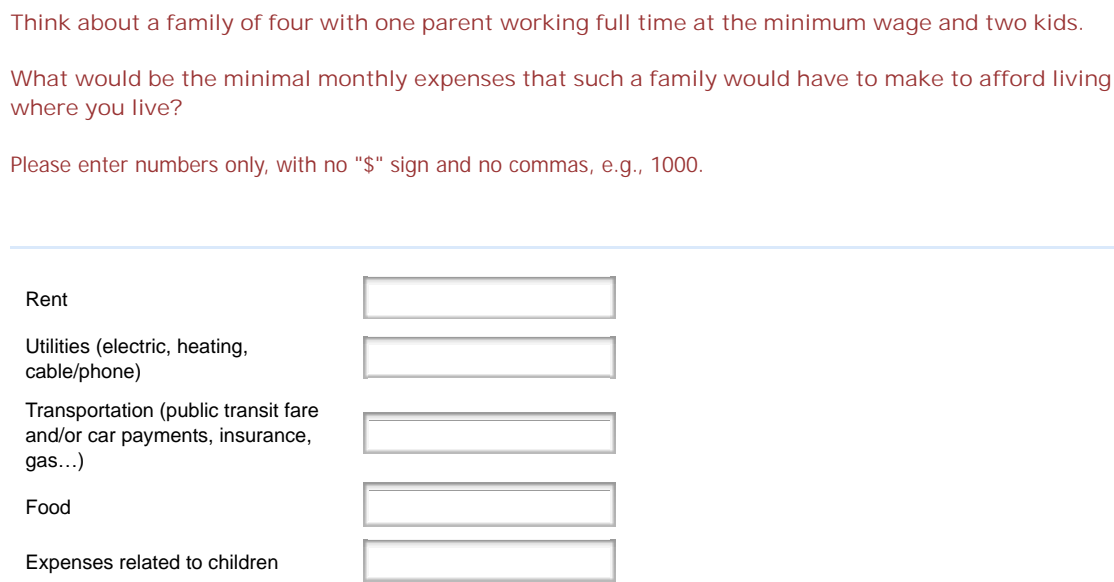

Notes: Available online at https://hbs .qualtrics.com/SE/?SID=SV_1B8MczKSMIvWaqx 
Appendix Table 1: Share of treatment respondents correctly answering basic comprehension questions

(1)

Percent that answered correctly

Pct of households earn less than 386,000

0.866

Pct of households earn less than 108,000

0.855

Pct of households earn less than 33,800

0.838

Household now making 386,000 would be making...

0.484

Household now making 108,000 would be making...

0.414

Household now making 33,800 would be making...

0.395

Observations

Notes: This table displays the percent of respondents who answered the comprehension questions correctly during the treatment (see the treatment screenshots in the Appendix for the complete wording and outlay of these questions).

Appendix Table 2: Ability of covariates to predict whether respondents finish the survey

\begin{tabular}{lcc}
\hline Variable & Coeff & P-val \\
\hline Voted for Obama in 2008 & 0.014 & 0.227 \\
Age & -0.003 & 0.000 \\
Liberal policy view & 0.002 & 0.676 \\
Household income & 0.001 & 0.449 \\
Married & 0.008 & 0.480 \\
Education & -0.001 & 0.724 \\
Male & 0.018 & 0.105 \\
Black & -0.006 & 0.765 \\
Hispanic & 0.072 & 0.007 \\
Native & -0.011 & 0.624 \\
Employed full time & -0.008 & 0.483 \\
Unemployed & 0.024 & 0.145 \\
Not in labor force & -0.029 & 0.055 \\
Student & 0.023 & 0.137 \\
Treatment Group & -0.113 & 0.000 \\
\hline
\end{tabular}

Notes: For each row, the coefficient and $p$-value are from regressions of the form Finished $_{i r}=$ $\alpha+\beta$ Covariate $_{i}+\delta_{r}+\epsilon_{i r}$, where Covariate is listed to the left in the row and $\delta_{r}$ are survey round fixed effects. 
Appendix Table 3: Attrition by survey round

\begin{tabular}{lcccc}
\hline Survey & \multicolumn{3}{c}{ Attrition } & Obs. (Completed) \\
\cline { 2 - 4 } & Control & Treatment & Differential & \\
\hline Omnibus & 0.09 & 0.21 & 0.11 & 4045 \\
Estate Tax & 0.06 & 0.03 & -0.03 & 1760 \\
Trust & 0.03 & 0.02 & -0.01 & 901 \\
Poverty & 0.03 & 0.02 & -0.01 & 1003 \\
Policy & 0.06 & 0.04 & -0.02 & 1114 \\
\hline
\end{tabular}

Notes: Note that the attrition numbers count those respondents who started and continued long enough to be at least assigned a treatment status. Respondents could drop out before being assigned to treatment for a variety of reasons, including that they were not U.S. citizens (albeit U.S. residents) or did not agree with the consent form. 
Appendix Table 4: Effect of omnibus treatment on all outcomes, part 1

\begin{tabular}{|c|c|c|c|c|c|c|c|c|c|c|c|c|}
\hline & $\frac{\text { Ineq vs. }}{(1)}$ & $\frac{\text { Ineq. inc. }}{(2)}$ & $\frac{\text { Deserving }}{(3)}$ & $\frac{\text { Top tax }}{(4)}$ & $\frac{\text { Mill. tax }}{(5)}$ & $\frac{\text { Estate tax }}{(6)}$ & $\frac{\text { Petition }}{(7)}$ & $\frac{\text { Min. wage }}{(8)}$ & $\frac{\text { Food stamps }}{(9)}$ & $\frac{\text { EITC }}{(10)}$ & $\begin{array}{c}\text { Trust } \\
(11)\end{array}$ & $\frac{\text { Scope }}{(12)}$ \\
\hline Treated & $\begin{array}{l}0.104^{* * *} \\
{[0.0144]}\end{array}$ & $\begin{array}{l}0.120^{* * *} \\
{[0.0128]} \\
\end{array}$ & $\begin{array}{c}-0.0526^{* * *} \\
{[0.0114]}\end{array}$ & $\begin{array}{l}0.931^{*} \\
{[0.549]} \\
\end{array}$ & $\begin{array}{c}0.0502^{* * *} \\
{[0.0126]}\end{array}$ & $\begin{array}{l}0.357^{* * *} \\
{[0.0140]} \\
\end{array}$ & $\begin{array}{c}0.0648^{* * *} \\
{[0.0156]} \\
\end{array}$ & $\begin{array}{c}0.0325^{* *} \\
{[0.0141]} \\
\end{array}$ & $\begin{array}{c}0.0149 \\
{[0.0141]}\end{array}$ & $\begin{array}{c}0.0212 \\
{[0.0151]} \\
\end{array}$ & $\begin{array}{c}-0.0292^{* *} \\
{[0.0115]} \\
\end{array}$ & $\begin{array}{l}0.132^{* * *} \\
{[0.0339} \\
\end{array}$ \\
\hline Cor & 0 & 0.738 & 0 & & & 0.171 & & & & 0.6 & 0. & 3.0 \\
\hline Scalec & 0.365 & 0.540 & 0.182 & 0.0914 & 0.111 & 2.043 & 0.394 & 0.0995 & 0.0369 & 0.0698 & 1.250 & 0.110 \\
\hline Obs. & 3703 & 3704 & 3690 & 3741 & 3704 & 3673 & 3060 & 3690 & 3690 & 3690 & 3702 & 3704 \\
\hline
\end{tabular}

Notes: The first three outcome variables are binary indicator variables, coded as one if the respondent says that "inequality is a very serious problem," "inequality has increased," and "the rich are deserving of their income," respectively. "Top rate" is continuous (respondents' preferred average tax rate on the richest one percent). "Mill. tax" and "Estate" indicate the respondent wants income taxes on millionaires and the estate tax to increase, respectively. "Petition" indicates she would write her Senator to increase the estate tax. "Min wage," "Food st." and "EITC" indicate support for increasing the minimum wage, and funding for SNAP and EITC, respectively. "Trust" indicates trust in government and "Scope" indicates the respondent favors a broad range of interventions by the government (1-5 categorical variable). "Covariates" and "scaled effects" are as specified in the notes to Table 4. The row "Control mean" reports the mean of the outcome variable in the control group. ${ }^{*} p<0.1,{ }^{* *} p<0.05,{ }^{* * *} p<0.01$ 
Appendix Table 5: Effect of omnibus treatment on all outcomes, part 2

\begin{tabular}{|c|c|c|c|c|c|c|c|c|c|}
\hline & $\frac{\text { Dem. } 2012}{(1)}$ & $\frac{\text { Taxes redistr. }}{(2)}$ & $\frac{\text { Growth }}{(3)}$ & $\frac{\operatorname{Tax} 1950}{(4)}$ & $\frac{\text { Satisfied }}{(5)}$ & $\frac{\text { Money charity }}{(6)}$ & $\frac{\text { Money given }}{(7)}$ & $\frac{\text { Time charity }}{(8)}$ & $\frac{\text { Time given }}{(9)}$ \\
\hline Treated & $\begin{array}{c}0.0152 \\
{[0.0125]}\end{array}$ & $\begin{array}{c}0.0396^{* * *} \\
{[0.0132]}\end{array}$ & $\begin{array}{l}0.137^{* * *} \\
{[0.0160]}\end{array}$ & $\begin{array}{l}0.131^{* * *} \\
{[0.0158]}\end{array}$ & $\begin{array}{l}-0.0266 \\
{[0.0264]}\end{array}$ & $\begin{array}{l}0.00717 \\
{[0.0157]}\end{array}$ & $\begin{array}{l}0.00565 \\
{[0.0158]}\end{array}$ & $\begin{array}{l}0.00188 \\
{[0.0160]}\end{array}$ & $\begin{array}{c}-0.00655 \\
{[0.0157]}\end{array}$ \\
\hline Control mean & 0.529 & 0.199 & 0.437 & 0.556 & 2.881 & 0.559 & 0.523 & 0.480 & 0.378 \\
\hline Scaled Effect & 0.0246 & 0.314 & 0.946 & 0.927 & 0.102 & 0.167 & 0.0823 & 0.0219 & 0.255 \\
\hline Obs. & 3703 & 3700 & 3696 & 3619 & 3690 & 3681 & 3683 & 3684 & 3684 \\
\hline
\end{tabular}

Notes: "Dem 2012" indicates the respondent plans to vote for the Democrat (Obama) in the 2012 Presidential election. "Taxes redistr." indicates that the respondent thinks the role of income taxes is to redistribute income. "Growth" indicates that the respondent correctly replied to the question of whether growth was higher in 1933-1980 than in 1980-2000. "Tax 1950" indicates that the respondent correctly replied to the question whether top income taxes were higher in the 1950s than today. "Satisfied" indicates whether the respondent is satisfied with his current income. "Money charity" (respectively, "Time charity") is a dummy variable for whether the respondent plans to give money (respectively, time) to charity in the next month and "Money given" (respectively, "Time given") indicates whether he has already given money (respectively, time) in the past month. "Covariates" and "scaled effects" are as specified in the notes to Table 4. The row "Control mean" reports the mean of the outcome variable in the control group. ${ }^{*} p<0.1,{ }^{* *} p<0.05,{ }^{* * *} p<0.01$ 
Appendix Table 6: Effect of omnibus treatment on all outcomes, part 3

\begin{tabular}{|c|c|c|c|c|c|c|}
\hline & \multicolumn{3}{|c|}{ Income due to effort Tax on top $1 \%$ Tax on next $9 \%$} & on next & Botton & - Botto \\
\hline & (1) & $(2)$ & $(3)$ & $(4)$ & $(5)$ & (6) \\
\hline Treated & $-0.0571^{* * *}$ & $0.931^{*}$ & -0.311 & $-0.593^{*}$ & 0.304 & 0.628 \\
\hline & {$[0.0152]$} & {$[0.549]$} & {$[0.380]$} & {$[0.341]$} & {$[0.442]$} & {$[0.428]$} \\
\hline Control mean & 0.419 & 30.21 & 17.60 & 10.71 & 18.93 & 11.28 \\
\hline Scaled Effect & 0.156 & 0.0914 & 0.195 & 0.232 & 0.0531 & 0.140 \\
\hline Obs. & 3689 & 3741 & 3740 & 3721 & 3741 & 3741 \\
\hline
\end{tabular}

Notes: "Income due to effort" is a binary variable indicating that the respondent believes that one's income is mostly the result of one's own effort. "Tax on top "\%", "Tax on next 9\%", "Tax on next $40 \%$ " and "Tax on Bottom 50\%" are the respondent's chosen tax rates for, respectively, people in the 99th percentile, 90th to 99th percentile, in the 50th to 90th percentile and in the Bottom half of the income distribution. "Top 1 tax - Bottom 50 tax" is the tax differential between the preferred tax on the top 1\% and that on the Bottom 50\%. "Covariates" and "scaled effects" are as specified in the notes to Table 4. The row "Control mean" reports the mean of the outcome variable in the control group. ${ }^{*} p<0.1,{ }^{* *} p<0.05,{ }^{* * *} p<0.01$ 
Appendix Table 7: Selection into the follow-up

\begin{tabular}{lcc}
\hline Variable & Coefficient & P-value \\
\hline Voted for Obama in 2008 & -0.001 & 0.957 \\
Age & 0.002 & 0.029 \\
Liberal policy view & -0.011 & 0.285 \\
Household income & 0.006 & 0.101 \\
Married & 0.056 & 0.014 \\
Education & 0.007 & 0.389 \\
Male & -0.009 & 0.677 \\
Black & 0.041 & 0.348 \\
Hispanic & 0.079 & 0.177 \\
Native & -0.059 & 0.216 \\
Employed full time & 0.003 & 0.897 \\
Unemployed & 0.004 & 0.901 \\
Not in labor force & 0.080 & 0.038 \\
Student & -0.064 & 0.020 \\
\hline
\end{tabular}

Notes: For each row, the coefficient and $p$-value are from regressions of the form

Followup $_{i r}=\alpha+\beta$ Covariate $_{i}+\epsilon_{i r}$, where Covariate is listed to the left in the row. Those tests are used to detect selection into the follow-up survey. 
Appendix Table 8: Effect of omnibus treatment one month later

\begin{tabular}{|c|c|c|c|c|c|c|c|c|}
\hline & \multicolumn{2}{|c|}{ Ineq. v. serious } & \multicolumn{2}{|c|}{ Ineq. inc. } & \multicolumn{2}{|c|}{ Rich deserving } & \multicolumn{2}{|c|}{ Top tax rate } \\
\hline & (1) & $(2)$ & $(3)$ & (4) & (5) & (6) & (7) & $(8)$ \\
\hline & First & Follow-up & First & Follow-up & First & Follow-up & First & Follow-up \\
\hline Treated & $\begin{array}{l}0.00833 \\
{[0.0809]}\end{array}$ & $\begin{array}{c}0.102 \\
{[0.0770]}\end{array}$ & $\begin{array}{c}0.0732 \\
{[0.0716]}\end{array}$ & $\begin{array}{l}-0.0160 \\
{[0.0786]}\end{array}$ & $\begin{array}{c}0.0589 \\
{[0.0799]}\end{array}$ & $\begin{array}{c}0.0195 \\
{[0.0785]}\end{array}$ & $\begin{array}{c}2.440 \\
{[3.602]}\end{array}$ & $\begin{array}{c}2.674 \\
{[3.547]}\end{array}$ \\
\hline Control mean & 0.283 & 0.218 & 0.785 & 0.756 & 0.166 & 0.128 & 32.86 & 30.76 \\
\hline Obs. & 145 & 145 & 145 & 145 & 145 & 145 & 144 & 144 \\
\hline
\end{tabular}

Notes: All outcomes are as defined previously. For each dependent variable, Col "First" is the result from the first survey, while Col

"Follow-up" is the result from the follow-up survey. All regressions include our standard controls. ${ }^{*} p<0.1,{ }^{* *} p<0.05,{ }^{* * *} p<0.01$

Appendix Table 9: Effect of omnibus treatment one month later (cont.)

\begin{tabular}{|c|c|c|c|c|c|c|c|c|}
\hline & \multicolumn{2}{|c|}{ Mill. tax } & \multicolumn{2}{|c|}{ Estate tax } & \multicolumn{2}{|c|}{ Trust gov. } & \multicolumn{2}{|c|}{ Govt scope } \\
\hline & (1) & $(2)$ & (3) & (4) & (5) & (6) & (7) & (8) \\
\hline & First & Follow-up & First & Follow-up & First & Follow-up & First & Follow-up \\
\hline Treated & -0.00817 & 0.0273 & $0.337^{* * *}$ & $0.195^{* *}$ & $-0.122^{* *}$ & -0.0691 & 0.259 & $0.364^{*}$ \\
\hline & {$[0.0801]$} & {$[0.0803]$} & {$[0.0953]$} & {$[0.0910]$} & {$[0.0611]$} & {$[0.0582]$} & {$[0.207]$} & {$[0.200]$} \\
\hline Control mean & 0.758 & 0.782 & 0.180 & 0.179 & 0.122 & 0.128 & 2.995 & 2.910 \\
\hline Obs. & 145 & 145 & 145 & 145 & 145 & 145 & 145 & 145 \\
\hline
\end{tabular}


Appendix Table 10: Bounding effects of attrition (using "liberal" and "conservative" values for outcomes)

\begin{tabular}{|c|c|c|c|c|c|c|c|c|}
\hline & \multicolumn{2}{|c|}{ Ineq. v. serious } & \multicolumn{2}{|c|}{ Increase Mill. Tax } & \multicolumn{2}{|c|}{ Increase Estate Tax } & \multicolumn{2}{|c|}{ Trust Gov } \\
\hline & (1) & $(2)$ & $(3)$ & (4) & $(5)$ & (6) & $(7)$ & (8) \\
\hline & $\mathrm{C}$ & $\mathrm{L}$ & $\mathrm{C}$ & $\mathrm{L}$ & $\mathrm{C}$ & $\mathrm{L}$ & $\mathrm{C}$ & $\mathrm{L}$ \\
\hline Treated & $\begin{array}{c}0.0666^{* * *} \\
{[0.0129]}\end{array}$ & $\begin{array}{c}0.0980^{* * *} \\
{[0.0128]}\end{array}$ & $\begin{array}{l}0.00915 \\
{[0.0120]}\end{array}$ & $\begin{array}{c}0.0503^{* * *} \\
{[0.0117]}\end{array}$ & $\begin{array}{l}0.284^{* * *} \\
{[0.0122]}\end{array}$ & $\begin{array}{l}0.310^{* * *} \\
{[0.0121]}\end{array}$ & $\begin{array}{c}-0.0232^{* *} \\
{[0.00970]}\end{array}$ & $\begin{array}{c}-0.0221^{* *} \\
{[0.00970]}\end{array}$ \\
\hline Cont & 0.267 & 0.293 & 0.709 & 0.743 & 0.170 & 0.192 & 0.159 & 0.159 \\
\hline Obs. & 4547 & 4547 & 4546 & 4546 & 4519 & 4519 & 4546 & 4546 \\
\hline
\end{tabular}

Notes: All outcomes are as defined previously. No controls are included. For each dependent variable, $\mathrm{Col} \mathrm{C}$ assumes that all attritors gave the average answer among those who label themselves as conservative or very conservative. Col $\mathrm{L}$ assumes that all attritors would have given the average answer among those who label themselves as liberal or very liberal. ${ }^{*} p<0.1,{ }^{* *} p<0.05,{ }^{* * *} p<0.01$ 
Appendix Table 11: Views on inequality and taxes for high- and low-attrition rounds in the omnibus surveys

\begin{tabular}{|c|c|c|c|c|c|c|c|c|c|c|c|c|}
\hline & \multicolumn{2}{|c|}{ Ineq. v. serious } & \multicolumn{2}{|c|}{ Ineq. increased } & \multicolumn{2}{|c|}{ Rich deserving } & \multicolumn{2}{|c|}{ Top tax rate } & \multicolumn{2}{|c|}{ Increase Mill. Tax } & \multicolumn{2}{|c|}{ Estate tax } \\
\hline & (1) & $(2)$ & $(3)$ & $(4)$ & $(5)$ & $(6)$ & $(7)$ & (8) & $(9)$ & $(10)$ & (11) & $(12)$ \\
\hline Treated & $\begin{array}{c}0.0794^{* * *} \\
{[0.0248]}\end{array}$ & $\begin{array}{c}0.117^{* * *} \\
{[0.0219]}\end{array}$ & $\begin{array}{c}0.0849^{* * *} \\
{[0.0222]}\end{array}$ & $\begin{array}{l}0.138^{* * *} \\
{[0.0176]}\end{array}$ & $\begin{array}{r}-0.00327 \\
{[0.0199]}\end{array}$ & $\begin{array}{c}-0.0672^{* * *} \\
{[0.0169]}\end{array}$ & $\begin{array}{c}0.155 \\
{[1.031]}\end{array}$ & $\begin{array}{c}2.003^{* * *} \\
{[0.716]}\end{array}$ & $\begin{array}{c}0.0183 \\
{[0.0210]}\end{array}$ & $\begin{array}{c}0.0555^{* * *} \\
{[0.0187]}\end{array}$ & $\begin{array}{l}0.421^{* * *} \\
{[0.0247]}\end{array}$ & $\begin{array}{l}0.365^{* * *} \\
{[0.0212]}\end{array}$ \\
\hline Control mean & 0.276 & 0.289 & 0.767 & 0.780 & 0.160 & 0.180 & 34.40 & 28.88 & 0.794 & 0.754 & 0.179 & 0.178 \\
\hline Scaled Effect & 0.278 & 0.387 & 0.475 & 0.615 & 0.0118 & 0.209 & 0.0131 & 0.203 & 0.0487 & 0.108 & 1.761 & 2.396 \\
\hline Differential attrition? & Low & High & Low & High & Low & High & Low & High & Low & High & Low & High \\
\hline Obs. & 1260 & 1635 & 1260 & 1636 & 1254 & 1631 & 1271 & 1650 & 1260 & 1636 & 1250 & 1626 \\
\hline
\end{tabular}

Notes: All outcomes are as defined previously. "Differential attrition?" separates observations according to whether they were in "Low" differential attrition round (round 4) or in "High" differential attrition rounds (rounds 1, 2 and 3). Otherwise, all terminology follows that in previous tables. ${ }^{*} p<0.1,{ }^{* *} p<0.05,{ }^{* * *} p<0.01$

Appendix Table 12: Opinions on other policies and views of government for high- and low-attrition rounds in the omnibus surveys

\begin{tabular}{|c|c|c|c|c|c|c|c|c|c|c|}
\hline & \multicolumn{2}{|c|}{ Min. wage } & \multicolumn{2}{|c|}{ EITC } & \multicolumn{2}{|c|}{ Food stamps } & \multicolumn{2}{|c|}{ Trust gov. } & \multicolumn{2}{|c|}{ Scope } \\
\hline & $(1)$ & $(2)$ & $(3)$ & $(4)$ & $(5)$ & (6) & $(7)$ & (8) & $(9)$ & $(10)$ \\
\hline Treated & $\begin{array}{l}0.00695 \\
{[0.0244]}\end{array}$ & $\begin{array}{l}0.0408^{*} \\
{[0.0210]}\end{array}$ & $\begin{array}{l}-0.0199 \\
{[0.0257]}\end{array}$ & $\begin{array}{c}0.0260 \\
{[0.0230]}\end{array}$ & $\begin{array}{c}0.0203 \\
{[0.0240]}\end{array}$ & $\begin{array}{c}0.0197 \\
{[0.0210]}\end{array}$ & $\begin{array}{c}-0.0630^{* * *} \\
{[0.0205]} \\
\end{array}$ & $\begin{array}{c}0.000987 \\
{[0.0169]} \\
\end{array}$ & $\begin{array}{c}0.0576 \\
{[0.0579]}\end{array}$ & $\begin{array}{l}0.248^{* * *} \\
{[0.0494]}\end{array}$ \\
\hline Control mean & 0.708 & 0.706 & 0.683 & 0.589 & 0.710 & 0.702 & 0.181 & 0.133 & 3.140 & 2.997 \\
\hline Scaled Effect & 0.0227 & 0.129 & 0.0679 & 0.0808 & 0.0490 & 0.0451 & 5.724 & 0.0311 & 0.0441 & 0.195 \\
\hline Differential attrition? & Low & High & Low & High & Low & High & Low & High & Low & High \\
\hline Obs. & 1254 & 1631 & 1254 & 1631 & 1254 & 1631 & 1259 & 1635 & 1260 & 1636 \\
\hline
\end{tabular}

Notes: See previous table. ${ }^{*} p<0.1,{ }^{* *} p<0.05,{ }^{* * *} p<0.01$ 
Appendix Table 13: Effect of estate-tax-only treatments on outcome variables

\begin{tabular}{|c|c|c|c|c|c|c|c|c|c|c|c|}
\hline & $\frac{\text { Ineq. vs. }}{(1)}$ & $\frac{\text { Ineq. inc. }}{(2)}$ & $\frac{\text { Estate corr. }}{(3)}$ & $\frac{\text { Pov. vs. }}{(4)}$ & $\frac{\text { Deserving }}{(5)}$ & $\frac{\text { Top tax }}{(6)}$ & $\frac{\text { Mill. tax }}{(7)}$ & $\frac{\text { Estate }}{(8)}$ & $\frac{\text { Petition }}{(9)}$ & $\frac{\text { Charities }}{(10)}$ & $\frac{\text { Educ. pol }}{(11)}$ \\
\hline Treated (Emotional) & $\begin{array}{c}0.0381 \\
{[0.0258]}\end{array}$ & $\begin{array}{c}-0.00239 \\
{[0.0243]}\end{array}$ & $\begin{array}{l}0.316^{* * *} \\
{[0.0263]}\end{array}$ & $\begin{array}{c}0.0224 \\
{[0.0274]}\end{array}$ & $\begin{array}{l}-0.0247 \\
{[0.0206]}\end{array}$ & $\begin{array}{c}1.595 \\
{[1.121]}\end{array}$ & $\begin{array}{l}0.00123 \\
{[0.0243]}\end{array}$ & $\begin{array}{l}0.289^{* * *} \\
{[0.0258]}\end{array}$ & $\begin{array}{c}0.0313 \\
{[0.0208]}\end{array}$ & $\begin{array}{c}0.0421 \\
{[0.0699]}\end{array}$ & $\begin{array}{l}-0.0319 \\
{[0.0755]}\end{array}$ \\
\hline Treated (Neutral) & $\begin{array}{c}0.0511^{* *} \\
{[0.0259]}\end{array}$ & $\begin{array}{c}-0.0501^{* *} \\
{[0.0244]}\end{array}$ & $\begin{array}{l}0.375^{* * *} \\
{[0.0264]}\end{array}$ & $\begin{array}{c}0.0191 \\
{[0.0276]}\end{array}$ & $\begin{array}{l}-0.0244 \\
{[0.0206]} \\
\end{array}$ & $\begin{array}{c}2.280^{* *} \\
{[1.124]} \\
\end{array}$ & $\begin{array}{r}-0.00456 \\
{[0.0244]} \\
\end{array}$ & $\begin{array}{c}0.109^{* * *} \\
{[0.0259]}\end{array}$ & $\begin{array}{c}0.0239 \\
{[0.0209]} \\
\end{array}$ & $\begin{array}{l}-0.0214 \\
{[0.0701]}\end{array}$ & $\begin{array}{c}0.0157 \\
{[0.0757]} \\
\end{array}$ \\
\hline Control mean & 0.307 & 0.771 & 0.120 & 0.285 & 0.174 & 33.67 & 0.717 & 0.210 & 0.132 & 1.945 & 3.611 \\
\hline Scaled Emot. Effect & 0.118 & 0.0106 & 3.386 & 0.0858 & 0.0984 & 0.142 & 0.00251 & 1.085 & 0.265 & 0.0329 & 0.0524 \\
\hline Scaled Neutral Effect & 0.159 & 0.223 & 4.014 & 0.0732 & 0.0974 & 0.202 & 0.00934 & 0.408 & 0.202 & 0.0167 & 0.0257 \\
\hline Obs. & 1777 & 1777 & 1773 & 1508 & 1777 & 1785 & 1764 & 1777 & 1762 & 1709 & 1732 \\
\hline
\end{tabular}

Notes: The "emotional" treatment repeats the estate tax slide from the omnibus treatment, but eliminates the rest of the treatment. The "neutral" treatment is a version of the "emotional" estate tax treatment that attempts to remove any framing effects. All outcomes are defined as previously. "Charities" and "Educ. pol" refer to the ranking (from 1 to 5, with 1 being the highest ranking) that respondents attribute to private charities and education policies as means to redistribute income. The lower number of observations in column 4 is due to the fact that this question was not asked in one smaller wave (sample of 300 ). ${ }^{*} p<0.1,{ }^{* *} p<0.05,{ }^{* * *} p<0.01$ 
Appendix Table 14: Effect of estate-tax-only treatment on outcome variables (cont.)

\begin{tabular}{|c|c|c|c|c|c|c|c|c|}
\hline & $\frac{\text { Min. wage }}{(1)}$ & $\frac{\text { Aid }}{(2)}$ & $\frac{\text { Food stamps }}{(3)}$ & $\frac{\text { Housing }}{(4)}$ & $\frac{\text { Trust }}{(5)}$ & $\frac{\text { Govt scope }}{(6)}$ & $\frac{\text { No waste }}{(7)}$ & $\frac{\text { Dem. } 2014}{(8)}$ \\
\hline Treated (Emotional) & $\begin{array}{c}0.0529 \\
{[0.0865]}\end{array}$ & $\begin{array}{c}0.109 \\
{[0.0837]}\end{array}$ & $\begin{array}{c}0.0982 \\
{[0.0861]}\end{array}$ & $\begin{array}{l}0.236^{* * *} \\
{[0.0824]}\end{array}$ & $\begin{array}{l}-0.0164 \\
{[0.0205]}\end{array}$ & $\begin{array}{c}0.0172 \\
{[0.0585]}\end{array}$ & $\begin{array}{l}-0.0281 \\
{[0.0303]}\end{array}$ & $\begin{array}{c}0.0344 \\
{[0.0213]}\end{array}$ \\
\hline Treated (Neutral) & $\begin{array}{l}-0.0838 \\
{[0.0870]}\end{array}$ & $\begin{array}{c}0.0273 \\
{[0.0842]}\end{array}$ & $\begin{array}{c}0.0628 \\
{[0.0866]}\end{array}$ & $\begin{array}{c}0.127 \\
{[0.0829]}\end{array}$ & $\begin{array}{c}-0.00558 \\
{[0.0205]}\end{array}$ & $\begin{array}{c}0.0259 \\
{[0.0587]}\end{array}$ & $\begin{array}{c}-0.0587^{*} \\
{[0.0303]}\end{array}$ & $\begin{array}{c}-0.00310 \\
{[0.0213]}\end{array}$ \\
\hline Control mean & 2.608 & 2.130 & 1.797 & 1.927 & 0.153 & 3.074 & 1.456 & 0.470 \\
\hline Scaled Emot. Effect & 0.0913 & 0.0624 & 0.0534 & 0.140 & 0.235 & 0.0150 & 0.0896 & 0.0490 \\
\hline Scaled Neutral Effect & 0.145 & 0.0156 & 0.0341 & 0.0755 & 0.0803 & 0.0225 & 0.187 & 0.00441 \\
\hline Obs. & 1495 & 1495 & 1495 & 1495 & 1756 & 1756 & 1754 & 1756 \\
\hline
\end{tabular}

Notes: See above. "No waste" takes values from 1 to 3, with 1 representing that the government is wasting a lot of tax revenue and 3 that the government is not wasting much tax revenue at all. Note that the only statistically significant effect for a poverty-related outcome is for increased public housing. We speculate that this effect is due to seeing the picture of the mansion in the "emotional" estate tax treatment (but not in the neutral treatment). The lower number of observations in columns 1-4 is due to the fact that these questions were not asked in one smaller wave (sample of 300). ${ }^{*} p<0.1,{ }^{* *} p<0.05,{ }^{* * *} p<0.01$ 
Appendix Table 15: Effect of trust treatment on outcome variables

\begin{tabular}{|c|c|c|c|c|c|c|c|c|}
\hline & $\frac{\text { Ineq. v. ser. }}{(1)}$ & $\frac{\text { Ineq. inc. }}{(2)}$ & $\frac{\text { Pov. v. ser. }}{(3)}$ & $\frac{\text { Deserving }}{(4)}$ & $\frac{\text { Top tax }}{(5)}$ & $\frac{\text { Mill. tax }}{(6)}$ & $\frac{\text { Estate }}{(7)}$ & $\frac{\text { Petition }}{(8)}$ \\
\hline Treated & $\begin{array}{l}0.0547^{*} \\
{[0.0311]} \\
\end{array}$ & $\begin{array}{c}0.0119 \\
{[0.0289]} \\
\end{array}$ & $\begin{array}{r}-0.00257 \\
{[0.0313]} \\
\end{array}$ & $\begin{array}{c}-0.0555^{* *} \\
{[0.0239]} \\
\end{array}$ & $\begin{array}{c}0.490 \\
{[1.326]} \\
\end{array}$ & $\begin{array}{l}-0.0421 \\
{[0.0275]} \\
\end{array}$ & $\begin{array}{c}-0.00168 \\
{[0.0266]} \\
\end{array}$ & $\begin{array}{c}-0.0602^{* *} \\
{[0.0236]} \\
\end{array}$ \\
\hline Control mean & 0.343 & 0.755 & 0.383 & 0.185 & 34.70 & 0.722 & 0.204 & 0.174 \\
\hline Scaled Trust Effect & 0.182 & 0.341 & 0.00828 & 0.204 & 0.0452 & 0.0949 & 0.00728 & 0.580 \\
\hline Obs. & 899 & 899 & 899 & 899 & 898 & 899 & 895 & 899 \\
\hline
\end{tabular}

Notes: The negative trust prime treatment consists of several multiple-choice questions that made respondents reflect on aspects of government they dislike. All terms are defined as previously. ${ }^{*} p<0.1,{ }^{* *} p<0.05,{ }^{* * *} p<0.01$

Appendix Table 16: Effect of trust treatment on outcome variables (cont.)

\begin{tabular}{|c|c|c|c|c|c|c|c|c|c|c|}
\hline & $\frac{\text { Min wage }}{(1)}$ & $\frac{\text { Aid }}{(2)}$ & $\frac{\text { Food st. }}{(3)}$ & $\frac{\text { Housing }}{(4)}$ & $\begin{array}{c}\text { Trust } \\
(5)\end{array}$ & $\frac{\text { Active }}{(6)}$ & $\frac{\text { No waste }}{(7)}$ & $\frac{\text { Dem. } 2014}{(8)}$ & $\frac{\text { Charity }}{(9)}$ & $\frac{\text { Educ. pol. }}{(10)}$ \\
\hline Treated & $\begin{array}{r}-0.00428 \\
{[0.0902]}\end{array}$ & $\begin{array}{c}-0.139^{* *} \\
{[0.0616]}\end{array}$ & $\begin{array}{c}-0.153^{* *} \\
{[0.0673]}\end{array}$ & $\begin{array}{c}-0.163^{* * *} \\
{[0.0614]}\end{array}$ & $\begin{array}{c}-0.0582^{* * *} \\
{[0.0203]}\end{array}$ & $\begin{array}{c}0.0236 \\
{[0.0688]}\end{array}$ & $\begin{array}{l}-0.0278 \\
{[0.0346]}\end{array}$ & $\begin{array}{c}-0.0462^{*} \\
{[0.0258]}\end{array}$ & $\begin{array}{c}0.187^{* *} \\
{[0.0791]}\end{array}$ & $\begin{array}{c}0.0615 \\
{[0.0885]}\end{array}$ \\
\hline Control mean & 2.673 & 2.675 & 2.454 & 2.581 & 0.125 & 3.031 & 1.423 & 0.479 & 1.800 & 3.732 \\
\hline Scaled Trust Effect & 0.00531 & 0.128 & 0.119 & 0.133 & 1.730 & 0.0170 & 0.109 & 0.0686 & 0.169 & 0.265 \\
\hline Obs. & 899 & 899 & 899 & 899 & 899 & 899 & 898 & 899 & 850 & 874 \\
\hline
\end{tabular}

Notes: See above. ${ }^{*} p<0.1,{ }^{* *} p<0.05,{ }^{* * *} p<0.01$ 
Appendix Table 17: Effect of "emotional" treatment on outcome variables

\begin{tabular}{|c|c|c|c|c|c|c|c|c|c|c|c|}
\hline & $\frac{\text { Ineq. v. ser. }}{(1)}$ & $\frac{\text { Ineq. inc. }}{(2)}$ & $\frac{\text { Pov. corr. }}{(3)}$ & $\frac{\text { Childpov. corr. }}{(4)}$ & $\frac{\text { Min wage corr. }}{(5)}$ & $\frac{\text { Pov. vs. }}{(6)}$ & $\frac{\text { Deserving }}{(7)}$ & $\frac{\text { Top tax }}{(8)}$ & $\frac{\text { Mill. tax }}{(9)}$ & $\frac{\text { Estate }}{(10)}$ & $\frac{\text { Petition }}{(11)}$ \\
\hline Treated & $\begin{array}{c}0.0783^{* * *} \\
{[0.0292]} \\
\end{array}$ & $\begin{array}{c}0.0410 \\
{[0.0258]} \\
\end{array}$ & $\begin{array}{l}0.258^{* * *} \\
{[0.0314]}\end{array}$ & $\begin{array}{c}-0.0717^{* *} \\
{[0.0298]} \\
\end{array}$ & $\begin{array}{l}0.0676^{* *} \\
{[0.0341]} \\
\end{array}$ & $\begin{array}{c}0.0885^{* * *} \\
{[0.0313]}\end{array}$ & $\begin{array}{l}-0.0131 \\
{[0.0228]}\end{array}$ & $\begin{array}{c}0.484 \\
{[1.268]} \\
\end{array}$ & $\begin{array}{c}0.0316 \\
{[0.0256]} \\
\end{array}$ & $\begin{array}{c}0.0149 \\
{[0.0274]} \\
\end{array}$ & $\begin{array}{c}-0.0000573 \\
{[0.0252]}\end{array}$ \\
\hline Control mean & 0.337 & 0.775 & 0.442 & 0.363 & 0.302 & 0.296 & 0.173 & 34.47 & 0.728 & 0.276 & 0.184 \\
\hline Scaled Poverty Effect & 0.221 & 0.225 & 17.54 & 1.522 & 1.105 & 0.257 & 0.0413 & 0.0357 & 0.0589 & 0.0440 & 0.000390 \\
\hline Obs. & 1002 & 1001 & 999 & 994 & 799 & 799 & 1002 & 1002 & 1001 & 999 & 1002 \\
\hline
\end{tabular}

Notes: The "emotional" treatment aimed at creating empathy between the respondent and families living in poverty. Respondents were told about poverty rates and had to fill out a minimum budget for a family like theirs living in the same city. Respondents were then shown how their minimum budget compared to the poverty line. All outcomes are as defined previously. The lower number of observations in columns 5 and 6 is due to the fact that these questions were not asked in one smaller wave (sample of 200 ). ${ }^{*} p<0.1,{ }^{* *} p<0.05,{ }^{* * *} p<0.01$

Appendix Table 18: Effect of "emotional" treatment on outcome variables (cont.)

\begin{tabular}{|c|c|c|c|c|c|c|c|c|c|c|}
\hline & $\frac{\text { Min wage }}{(1)}$ & $\begin{array}{c}\text { Aid } \\
(2)\end{array}$ & $\frac{\text { Food st. }}{(3)}$ & $\frac{\text { Housing }}{(4)}$ & $\frac{\text { Trust }}{(5)}$ & $\frac{\text { Scope }}{(6)}$ & $\frac{\text { No waste }}{(7)}$ & $\frac{\text { Dem. } 2014}{(8)}$ & $\frac{\text { Charity }}{(9)}$ & $\frac{\text { Educ. pol }}{(10)}$ \\
\hline Treated & $\begin{array}{c}0.0469 \\
{[0.0989]}\end{array}$ & $\begin{array}{c}0.117^{*} \\
{[0.0665]}\end{array}$ & $\begin{array}{l}0.177^{*} \\
{[0.101]}\end{array}$ & $\begin{array}{c}0.0397 \\
{[0.0670]}\end{array}$ & $\begin{array}{r}-0.00979 \\
{[0.0211]}\end{array}$ & $\begin{array}{c}0.0537 \\
{[0.0626]}\end{array}$ & $\begin{array}{c}-0.0655^{*} \\
{[0.0334]}\end{array}$ & $\begin{array}{c}0.0120 \\
{[0.0234]}\end{array}$ & $\begin{array}{c}0.0608 \\
{[0.0715]}\end{array}$ & $\begin{array}{l}-0.145^{*} \\
{[0.0831]}\end{array}$ \\
\hline Control mean & 2.546 & 2.559 & 1.832 & 2.539 & 0.124 & 3.098 & 1.420 & 0.488 & 1.929 & 3.723 \\
\hline Scaled Poverty Effect & 0.0449 & 0.0714 & 0.0866 & 0.0291 & 0.0931 & 0.0352 & 0.210 & 0.0181 & 0.0333 & 0.204 \\
\hline Obs. & 799 & 799 & 799 & 799 & 1002 & 1002 & 1002 & 1002 & 963 & 981 \\
\hline
\end{tabular}

Notes: See above. ${ }^{*} p<0.1,{ }^{* *} p<0.05,{ }^{* * *} p<0.01$ 
Appendix Table 19: Effect of policy treatment on outcome variables

\begin{tabular}{|c|c|c|c|c|c|c|c|c|c|c|c|}
\hline & $\frac{\text { Ineq. v. ser. }}{(1)}$ & $\frac{\text { Ineq. inc. }}{(2)}$ & $\frac{\text { Pov. corr. }}{(3)}$ & $\frac{\text { Childpov. corr. }}{(4)}$ & $\frac{\text { Min wage corr. }}{(5)}$ & $\frac{\text { Pov. vs. }}{(6)}$ & $\frac{\text { Deserving }}{(7)}$ & $\frac{\text { Top tax }}{(8)}$ & $\frac{\text { Mill. tax }}{(9)}$ & $\frac{\text { Estate }}{(10)}$ & $\frac{\text { Petition }}{(11)}$ \\
\hline Treated & $\begin{array}{c}0.0405 \\
{[0.0279]}\end{array}$ & $\begin{array}{c}0.0206 \\
{[0.0263]}\end{array}$ & $\begin{array}{c}0.0353 \\
{[0.0306]}\end{array}$ & $\begin{array}{c}0.0369 \\
{[0.0302]}\end{array}$ & $\begin{array}{l}0.228^{* * *} \\
{[0.0300]}\end{array}$ & $\begin{array}{r}-0.00637 \\
{[0.0272]}\end{array}$ & $\begin{array}{c}-0.00219 \\
{[0.0219]}\end{array}$ & $\begin{array}{l}2.023^{*} \\
{[1.209]}\end{array}$ & $\begin{array}{c}0.0311 \\
{[0.0240]}\end{array}$ & $\begin{array}{l}-0.0217 \\
{[0.0258]}\end{array}$ & $\begin{array}{l}-0.0222 \\
{[0.0236]}\end{array}$ \\
\hline Control mean & 0.343 & 0.744 & 0.415 & 0.365 & 0.355 & 0.326 & 0.180 & 33.79 & 0.713 & 0.269 & 0.187 \\
\hline Scaled Policy Effect & 0.108 & 0.0892 & 0.909 & 1.056 & 7.237 & 0.0196 & 0.00695 & 0.140 & 0.0536 & 0.0642 & 0.131 \\
\hline Obs. & 1111 & 1111 & 1105 & 1107 & 1110 & 1111 & 1111 & 1111 & 1110 & 1110 & 1111 \\
\hline
\end{tabular}

Notes: The policy treatment aimed at creating empathy between the respondent and families living on a minimum wage. Respondents had to fill out a minimum budget for a family like theirs living in the same city. Respondents were then shown how their minimum budget compared to the minimum wage and how food stamps adds $\$ 150$ per person/month to the budget of such a family. All outcomes are as defined previously. ${ }^{*} p<0.1,{ }^{* *} p<0.05,{ }^{* * *} p<0.01$

Appendix Table 20: Effect of policy treatment on outcome variables (cont.)

\begin{tabular}{|c|c|c|c|c|c|c|c|c|c|c|}
\hline & $\frac{\text { Min wage }}{(1)}$ & $\frac{\text { Aid }}{(2)}$ & $\frac{\text { Food st. }}{(3)}$ & $\frac{\text { Housing }}{(4)}$ & $\frac{\text { Trust }}{(5)}$ & $\frac{\text { Scope }}{(6)}$ & $\frac{\text { No waste }}{(7)}$ & $\frac{\text { Dem. } 2014}{(8)}$ & $\frac{\text { Charity }}{(9)}$ & $\frac{\text { Educ. pol. }}{(10)}$ \\
\hline Treated & $\begin{array}{l}0.323^{* * *} \\
{[0.0949]}\end{array}$ & $\begin{array}{l}0.133^{* *} \\
{[0.0638]}\end{array}$ & $\begin{array}{l}0.313^{* * *} \\
{[0.0970]}\end{array}$ & $\begin{array}{l}0.176^{* * *} \\
{[0.0636]}\end{array}$ & $\begin{array}{l}-0.0325 \\
{[0.0207]}\end{array}$ & $\begin{array}{c}0.0569 \\
{[0.0613]}\end{array}$ & $\begin{array}{l}-0.0428 \\
{[0.0308]}\end{array}$ & $\begin{array}{c}0.0248 \\
{[0.0223]}\end{array}$ & $\begin{array}{l}-0.137^{*} \\
{[0.0709]}\end{array}$ & $\begin{array}{c}-0.117 \\
{[0.0797]}\end{array}$ \\
\hline $\begin{array}{l}\text { Control mean } \\
\text { Scaled Policy Effect } \\
\text { Obs. }\end{array}$ & $\begin{array}{c}2.546 \\
0.310 \\
806\end{array}$ & $\begin{array}{c}2.559 \\
0.0811 \\
806\end{array}$ & $\begin{array}{c}1.832 \\
0.153 \\
806\end{array}$ & $\begin{array}{c}2.539 \\
0.129 \\
806\end{array}$ & $\begin{array}{c}0.149 \\
0.654 \\
1111\end{array}$ & $\begin{array}{c}3.097 \\
0.0362 \\
1111\end{array}$ & $\begin{array}{c}1.394 \\
0.125 \\
1111\end{array}$ & $\begin{array}{c}0.484 \\
0.0354 \\
1111\end{array}$ & $\begin{array}{c}2.025 \\
0.0740 \\
1068\end{array}$ & $\begin{array}{c}3.699 \\
0.186 \\
1085\end{array}$ \\
\hline
\end{tabular}

Notes: See above. The lower number of observations in columns 1-4 is due to the fact that these questions were not asked in one smaller wave (sample of 300$) .{ }^{*} p<0.1,{ }^{* *} p<0.05,{ }^{* * *} p<0.01$ 